\title{
High fat-fed GPR55 null mice display impaired glucose tolerance without concomitant changes in energy balance or insulin sensitivity but are less responsive to the effects of the cannabinoids rimonabant or $\Delta(9)$-tetrahydrocannabivarin on weight gain
}

\author{
Edward T Wargent ${ }^{1}$, Malgorzata Kepczynska ${ }^{2}$, mohamed sghaier zaibi ${ }^{1}$, David C Hislop ${ }^{2}$, Jonathan RS Arch ${ }^{1}$, \\ Claire J Stocker \\ ${ }^{1}$ Institute of Translational Medicine, University of Buckingham, Buckingham, United Kingdom \\ 2 Medical School, University of Buckingham, Buckingham, United Kingdom \\ Corresponding Author: Claire J Stocker \\ Email address: claire.stocker@buckingham.ac.uk
}

Background The insulin-sensitizing phytocannabinoid, $\Delta(9)$-tetrahydrocannabivarin (THCV) can signal partly via G-protein coupled receptor-55 (GPR55 behaving as either an agonist or an antagonist depending on the assay). The cannabinoid receptor type 1 (CB1R) inverse agonist rimonabant is also a GPR55 agonist under some conditions. Previous studies have shown varied effects of deletion of GPR55 on energy balance and glucose homeostasis in mice. The contribution of signalling via GPR55 to the metabolic effects of THCV and rimonabant has been little studied. Methods In a preliminary experiment, energy balance and glucose homeostasis were studied in GPR55 knockout and wild-type mice fed on both standard chow (to 20 weeks of age) and high fat diets (from 6 to 15 weeks of age). In the main experiment, all mice were fed on the high fat diet (from 6 to 14 weeks of age). In addition to replicating the preliminary experiment, the effects of once daily administration of THCV (15 mg. $\mathrm{kg}^{-1} \mathrm{po}$ ) and rimonabant (10 mg. $\mathrm{kg}^{-1} \mathrm{po}$ ) were compared in the two genotypes. Results There was no effect of genotype on absolute body weight or weight gain, body composition measured by either dual-energy X-ray absorptiometry or Nuclear Magnetic Resonance (NMR), fat pad weights, food intake, energy expenditure, locomotor activity, glucose tolerance or insulin tolerance in mice fed on chow. When the mice were fed a high fat diet, there was again no effect of genotype on these various aspects of energy balance. However, in both experiments, glucose tolerance was worse in the knockout than the wild-type mice. Genotype did not affect insulin tolerance in either experiment. Weight loss in rimonabant- and THCV-treated mice was lower in knockout than in wild-type mice, but surprisingly there was no detectable effect of genotype on the effects of the drugs on any aspect of glucose homeostasis after taking into account the Peer) reviewing PDF | (2020:04:47549:2:0:NEW 3 Aug 2020) 
effect of genotype in vehicle-treated mice. Conclusions Our two experiments differ from those reported by others in finding impaired glucose tolerance in GPR55 knockout mice in the absence of any effect on body weight, body composition, locomotor activity or energy expenditure. Nor could we detect any effect of genotype on insulin tolerance, so the possibility that GPR55 regulates glucose-stimulated insulin secretion merits further investigation. By contrast with the genotype effect in untreated mice, we found that THCV and rimonabant reduced weight gain, and this effect was in part mediated by GPR55. 
1 High fat-fed GPR55 null mice display impaired glucose tolerance without concomitant changes in 2 energy balance or insulin sensitivity but are less responsive to the effects of the cannabinoids

3 rimonabant or $\Delta(9)$-tetrahydrocannabivarin on weight gain

4

5 Edward Taynton Wargent ${ }^{1}$, Małgorzata Anna Kępczyńska ${ }^{2}$, Mohamed Sghaier Zaibi ${ }^{1}$, David C

6 Hislop ${ }^{2}$, Jonathan Robert S Arch ${ }^{1}$, Claire Joanne Stocker ${ }^{2}$

$7 \quad{ }^{1}$ Institute of Translational Medicine, University of Buckingham, Hunter Street, Buckingham, MK18

8 1EG, UK.

$9 \quad{ }^{2}$ Medical School, University of Buckingham, Hunter Street, Buckingham, MK18 1EG, UK.

Corresponding Author: Claire Stocker 


\section{Background}

The insulin-sensitizing phytocannabinoid, $\Delta(9)$-tetrahydrocannabivarin (THCV) can signal partly via G-protein coupled receptor-55 (GPR55 behaving as either an agonist or an antagonist depending on the assay). The cannabinoid receptor type 1 (CB1R) inverse agonist rimonabant is also a GPR55 agonist under some conditions. Previous studies have shown varied effects of deletion of GPR55 on energy balance and glucose homeostasis in mice. The contribution of signalling via GPR55 to the metabolic effects of THCV and rimonabant has been little studied.

\section{Methods}

In a preliminary experiment, energy balance and glucose homeostasis were studied in GPR55 knockout and wild-type mice fed on both standard chow (to 20 weeks of age) and high fat diets (from 6 to 15 weeks of age). In the main experiment, all mice were fed on the high fat diet (from 6 to 14 weeks of age). In addition to replicating the preliminary experiment, the effects of once daily administration of THCV $\left(15 \mathrm{mg}^{\mathrm{kg}} \mathrm{kg}^{-1} \mathrm{po}\right)$ and rimonabant (10 $\left.\mathrm{mg}^{\mathrm{kg}}{ }^{-1} \mathrm{po}\right)$ were compared in the two genotypes.

\section{Results}

There was no effect of genotype on absolute body weight or weight gain, body composition measured by either dual-energy X-ray absorptiometry or Nuclear Magnetic Resonance (NMR), fat pad weights, food intake, energy expenditure, locomotor activity, glucose tolerance or insulin tolerance in mice fed on chow. When the mice were fed a high fat diet, there was again no effect of genotype on these various aspects of energy balance. However, in both experiments, glucose tolerance was worse in the knockout than the wildtype mice. Genotype did not affect insulin tolerance in either experiment. Weight loss in rimonabant- and THCV-treated mice was lower in knockout than in wild-type mice, but surprisingly there was no detectable effect of genotype on the effects of the drugs on any aspect of glucose homeostasis after taking into account the effect of genotype in vehicle-treated mice.

\section{Conclusions}

Our two experiments differ from those reported by others in finding impaired glucose tolerance in GPR55 knockout mice in the absence of any effect on body weight, body composition, locomotor activity or energy expenditure. Nor could we detect any effect of genotype on insulin tolerance, so the possibility that GPR55 regulates glucose-stimulated insulin secretion merits further investigation. By contrast with the genotype effect in untreated mice, we found that THCV and rimonabant reduced weight gain, and this effect was in part mediated by GPR55. 


\section{Introduction}

51 Previous work from our laboratory has shown that the plant-derived cannabinoid, $\Delta(9)$ 52 tetrahydrocannabivarin (THCV) improves insulin sensitivity in diet-induced obese and ob/ob mice (Wargent et al., 2013) but it is not clear which receptor or receptors mediate its effects. Cannabinoids, signal partly via GPR55 (Pertwee, 2007; Sharir and Abood, 2010). THCV was a high efficacy, low affinity agonist of ERK1/2 phosphorylation when hGPR55 was expressed in HEK293 cells but it inhibited L-alysophosphatidylinositol signalling (Anavi-Goffer et al., 2012). The cannabinoid receptor type 1 (CB1R) inverse agonist rimonabant, which was in the past used for the treatment of obesity, is also a GPR55 agonist (Kapur et al., 2009; Henstridge et al., 2010), although under some conditions it can behave as an antagonist (Lauckner et al., 2008; Anavi-Goffer et al., 2012).

60

There is conflicting evidence as to whether GPR55 agonists or antagonists might be of benefit in the treatment of obesity or type 2 diabetes (Lipina et al., 2012; Moreno-Navarrete et al., 2012; Henstridge et al., 2016). Some findings in humans suggest that GPR55 receptor antagonists should reduce food intake and body weight (Henstridge et al., 2016). By contrast, in support of GPR55 agonists, two studies found that GPR55 knockout mice showed increased adiposity and insulin resistance associated with decreased locomotor activity (Meadows et al., 2016, Lipina et al., 2019), although another failed to demonstrate increased adiposity and locomotor activity was actually increased during the first six hours of the dark period (Bjursell et al., 2016). Further support for the potential of GPR55 agonists in the treatment of type 2 diabetes comes from two studies that have found that the GPR55 agonist O-1602 stimulated insulin secretion from wild-type but not GPR55 -/- murine islets of Langerhans (Romero-Zerbo et al., 2011; Liu et al., 2016). In one of these studies (Romero-Zerbo et al., 2011), it was also shown that O-1602 stimulated insulin secretion and improved glucose tolerance in vivo in rats.

Previous studies in GPR55 knockout mice have mostly been conducted using mice fed on a standard chow diet. Here we first compared GPR55 knockout and wild-type mice fed on both standard chow and high fat diets. We found that oral glucose tolerance was worse in GPR55 knockout than in wild-type mice when the mice were fed on a high fat diet but not when they are fed on a chow diet. To investigate the role of GPR55 in responses to THCV and rimonabant, we therefore compared metabolic responses to these drugs in wild type and GPR55 knockout mice fed on a high fat diet. We report that THCV and especially rimonabant had less effect on body weight gain in GPR55 knockout than in wild-type mice but we were unable to demonstrate genotype influenced changes in glucose homeostasis in response to THCV or rimonabant.

\section{Materials and Methods}

\section{Mice}

Two male and five female GPR55+/- mice on a C57BI/6 background were kindly supplied, with the permission of AstraZeneca, Macclesfield, UK, by Professor Cherry Wainwright of the Institute for Health 
84

85

86

87

88

89

90

91

and Welfare Research, The Robert Gordon University Aberdeen AB10 1FR, UK. They were bred to produce GPR55-/- ('knockout') and wild-type mice. The final breeding-round for the current studies was between homozygous wild-type or knockout mice.

In the preliminary experiment, the purpose of which was solely to compare the phenotypes of wild-type and GPR55 knockout mice, the intention was to use 12 wild-type and 12 knockout male mice in each experiment (chow-fed or high fat diet-fed), housed in pairs. Only 11 knockout mice were available for the high fat diet experiment, however.

In the main experiment, which focussed on mice fed on a high fat diet and investigated whether responses to THCV (15 mg. $\mathrm{kg}^{-1}$ po once daily; GW Research Ltd, Cambridge, UK) and rimonabant (10 mg. $\mathrm{kg}^{-1}$ po once daily) differed between genotypes, the intention was again to use 12 wild-type and 12 knockout mice, housed in pairs, in each group. However, one mouse died before the experimental period began, one mouse died in each of the control groups, and one mouse died in the rimonabant wild-type group (tumour found in chest). All data for these mice have been excluded. The vehicle for both THCV and rimonabant was $2.5 \%$ ethanol in sesame seed oil $\left(10 \mathrm{ml} \cdot \mathrm{kg}^{-1}\right)$.

The mice were housed at $24-26^{\circ} \mathrm{C}$ with lights on at 08:00 and off at 20:00. Mice were housed in pairs in the preliminary study and 3 per cage in the main study. They were fed at weaning on chow (Beekay rat and mouse diet No 1; BK001E; Beekay Feed, B\&K Universal Limited) and from six weeks of age on a high fat diet (metabolizable energy: $60 \%$ fat; $20 \%$ carbohydrate; $20 \%$ protein; Research Diets, New Brunswick, NJ, USA; product \#D12492). Food and water were provided ad libitum. Cages had solid bases with sawdust for foraging and digging. Cotton fibre nestlets and Enviro-Dri paper were provided as bedding and cover. Cardboard houses and tunnels were also provided for shelter, exploration, and gnawing. Wood chew sticks were also provided for gnawing. Interlocking PVC sections were used for climbing and compartmentalisation.

All procedures involving animals were conducted in accordance with the University of Buckingham Animals (Scientific Procedures) Act 1986 (ASPA) Ethical Review Board and theASPA Project Licence (PPL) licence number: 70/7164).). ARRIVE guidelines were followed in the reporting of the experiments. Mice were inspected daily for adverse effects and after every procedure. At the end of the study all mice were killed by concussion of the brain by striking the cranium followed by cervical dislocation.

Criteria for euthanizing animals before the end of study were as follows. Any animal showing signs of misdosing or damage after oral gavage, such as by coughing/choking or collapsing after administration of substances will be killed by an approved method. Animals receiving intraperitoneal dosing will be observed immediately after dosing and if treatment is for a prolonged period, we will monitor the animals for signs of pain and distress that may indicate peritonitis (hunching, subdued behaviour, hind limb extension). Any animal showing signs of damage will be humanely killed. Following blood sampling animals showing lasting 
118

signs of damage or exceeding the mild severity limit will be humanely killed. In the insulin sensitivity tests any animal that shows signs of torpor after insulin administration will immediately be given glucose and/or glucagon by the intra-peritoneal route, monitored continuously and killed if it fails to respond to stimulation or does not recover within 20 minutes. None of these criteria was necessary to be implemented in the preliminary study. Four animals in the main study experienced distress due to oral mis-dosing and were culled by concussion followed by cervical dislocation. This incidence rate was within the expected maximum of less than 1 in a thousand doses set out in the terms of the project licence.

\section{Experimental Methods}

Energy expenditure was measured by open circuit indirect calorimetry with mice in their home cages (Arch et al., 2006).

For the measurement of locomotor activity, mice were kept in the cages $(28 \times 12 \mathrm{~cm})$ in which they normally housed. They remained in their pairs. Video camera shots were taken every hour for 10 min, beginning 1 hour before the dark period. Thus, the first recording was at 19:00 and the last at 08:00. The recordings were digitally divided by black lines into three equal rectangles after filming. Horizontal locomotor activity was assessed by one independent observer from the number of times a mouse crossed a line during those 10 minutes in a blinded study.

Body fat and lean content was measured using a Minispec LF90 ॥I Nuclear Magnetic Resonance (Bruker Corporation, Germany). Dual-energy X-ray absorptiometry (DXA or DEXA) was also used in the preliminary experiment because it gives a measure of bone density, and it has been reported that bone structure is altered in GPR55 knockout mice (Whyte et al., 2009).

Insulin tolerance was measured after mice had been fasted for five hours before being dosed with insulin (Actrapid $^{\mathrm{TM}}$ (Centaur Services, UK) at 0.5 units/kg body weight, i.p. for chow-fed mice and 0.75 units $/ \mathrm{kg}$ bodyweight for high fat diet-fed mice). Blood samples for glucose measurement were taken $10 \mathrm{~min}$ and immediately before, and 10, 20, 3045 and 60 min after the administration of insulin.

Pancreatic insulin concentration and content were measured at termination. The mice were fasted from 09:00 and humanely killed at 14:00. Pancreatic insulin content (Wang et al. 2002), liver glycogen (Pearce et al. 2004), blood glucose and insulin, liver triglycerides and oral glucose and intraperitoneal insulin tolerance tests (Wargent et al. 2013) were conducted as described previously.

\section{Statistics}

Results given in the text, and data-points in the figures are shown as the mean \pm SEM. Sample size was calculated by the resource equation method (Festing and Altman, 2002). All data sets passed the Anderon- 
150

151

152

153

154

155

156

157

158

159

160

Darling test for normality of distribution (alpha of 0.05). The statistical significance of any differences between vehicle-treated animals and drug-treated animals was determined using Student's t-test, or where there were multiple treatments or time-points, 1-way or 2-way ANOVA followed by False Discovery Rate post-tests (FDR; two-stage linear step-up procedure of Benjamini, Krieger and Yekutieli), using Prism 7. ROUT was used to analyse data sets for outliers with no outliers being identified. In the FDR test $Q$ (adjusted $P$ value) is the lowest value that gave 'Yes' in the Discovery column of the analysis. Statistical significance is shown as: ${ }^{\star} P$ or $Q<0.05,{ }^{* *} P$ or $Q<0.01$; ${ }^{* * *} P$ or $Q<0.001 ;{ }^{* * * *} P$ or $Q<0.0001$.

\section{Results}

\section{Preliminary experiment}

The mice were fed on chow and then some were fed on a high fat diet from 6 weeks of age.

Weight gain was significantly greater $(Q<0.0001$ for both wildtype and knockout mice) between 6 and 11 weeks of age in mice fed on a high fat diet (wild type: $12.6 \pm 0.9 \mathrm{~g}, \mathrm{n}=12$; knockout:12.2 $\pm 1.3 \mathrm{~g}, \mathrm{n}=11$ ) than in mice fed on chow (wild type: $6.1 \pm 0.4 \mathrm{~g}, \mathrm{n}=12$; knockout: $5.2 \pm 0.4 \mathrm{~g}, \mathrm{n}=12$ ). However, irrespective of diet, there was no statistically significant effect of genotype on absolute body weight or weight gain (Figure 1), body composition measured by either DXA or NMR, fat pad weights, food intake, energy expenditure or locomotor activity (Table 1 for chow-fed mice; Table 2 for high fat-fed mice); nor on the time courses of energy expenditure and locomotor activity (results not shown, but are in the supplementary data file).

In the chow-fed mice, two-way ANOVA with time matching showed no effect of genotype on blood glucose in the glucose tolerance test (Figure $2 \mathrm{~A}$ ). There was no effect of genotype on plasma insulin at +30 or -30 min relative to the administration of glucose (Figure 2B). Insulin tolerance, whether expressed in terms of absolute blood glucose levels or the fall in blood glucose following injection of insulin, was no different between genotypes in the chow-fed mice at 20 weeks of age in either absolute blood glucose concentrations (Figure 2C) or in change in blood glucose (Figure 2D).

By contrast with the chow-fed mice, there were clear effects of genotype on blood glucose and plasma insulin in the glucose tolerance test and on insulin tolerance in the mice fed on the high fat diet (Figure 3). Thus, two-way ANOVA with time-matching followed by the FDR test showed that blood glucose was higher in the knockout than the wild-type mice 30 and 60 min after dosing with glucose $(Q<0.01$; Figure $3 A)$, and two-way ANOVA followed by the FDR test showed that plasma insulin was also higher in the knockout than the wild-type mice 30 min after administration of glucose $(Q<0.01$; Figure $3 B)$. 
181

182

183

184

185

186

187

Blood glucose 20 to 60 min after administration of insulin in the insulin tolerance test was higher in the knockout mice $(Q<0.01$; Figure $3 C)$. However, the fall in blood glucose following the injection of insulin was not significantly different between genotypes (Figure 3D).

Liver weight, liver glycogen and lipid contents, pancreatic insulin concentration and pancreatic total insulin content were not affected by genotype irrespective of diet (results not shown, but are in the supplementary data file).

\section{Main experiment}

The effects of $15 \mathrm{mg} \cdot \mathrm{kg}^{-1}$ po THCV and $10 \mathrm{mg} \cdot \mathrm{kg}^{-1}$ po rimonabant were compared between wild-type and GPR55 knockout mice fed on the high fat diet.

\section{Confirmation of results of preliminary experiment}

It was confirmed (for mice fed on a high fat diet) that energy balance is no different between GPR55 knockout and wild-type mice. The mean body weight of the vehicle-treated knockout mice was less than that of the vehicle-treated wild-type mice from the beginning of the study, but differences in body weight were not statistically significant at this or any other time. Analysis of body weight change showed higher increases in body weight for the knockout mice at 21, 28 and 35 days, but by 56 days the wild-type mice had the higher increase (Figure 4A) and there was no overall effect on genotype on body weight gain. As in the preliminary study, genotype had no effect on food intake (results not shown, but are in the supplementary data file), energy expenditure (Figure 5), body composition measurements (Figure 6) or fat pad weights (Table 3 ).

It was confirmed that glucose homeostasis is deficient in GPR55 knockout mice. As in the untreated mice in the preliminary study, blood glucose was higher in the vehicle-treated knockout than in the vehicle-treated wild-type mice $30 \mathrm{~min}(Q<0.01)$ and $60 \mathrm{~min}(Q<0.05)$ after giving glucose in the glucose tolerance test on day 21 (Figure 7A) and plasma insulin 30 min after giving glucose was higher in the vehicle-treated knockout mice than in the vehicle-treated wild-type mice $(Q<0.05$; Figure $8 A)$.

Although the same trend was seen as in the preliminary experiment, there was no significant difference in the insulin tolerance curves on day 38 between the vehicle-treated knockout mice and the vehicle-treated wild-type mice (Figures 9A and 9B). As in the preliminary experiment, there was also no difference in the fall in blood glucose when the data were normalised to the $0 \mathrm{~min}$ blood glucose values (Figures 9C and 9D) or the -10 min values (data not shown, but are in the supplementary data file).

\section{Responses to THCV and rimonabant: energy balance}

Two-way ANOVA with time-matching showed an overall effect of genotype on body weight gain in response to both THCV $(P<0.001$; Figure 4B) and rimonabant $(P<0.001$; Figure $4 \mathrm{C})$ from day 8 due to both THCV 
213 and rimonabant being less effective in the knockout mice. Although the effect of genotype on body weight 214 gain in THCV-treated mice was statistically significant on days prior to day 56 and over all days, it was not 215 statistically significant for THCV on the final day (day 56), being only $19 \%$ less in knockout than in wild-type 216 mice (6.7 g different from control in wild-type mice; $5.5 \mathrm{~g}$ different from controls in knockout mice). By 217 contrast, the effect of rimonabant on body weight gain on day 56 was significant, being $33 \%$ less in knockout 218 than wild-type mice (10.2 $\mathrm{g}$ different from control in wild-type mice: $6.8 \mathrm{~g}$ different from controls in knockout 219 mice). Two-way ANOVA (treatment; genotype) of the weight changes on day 56 did not show an interaction 220 between the effects of genotype and treatment $(P=0.06)$, so it cannot be claimed that GPR55 contributed more to the effect of rimonabant on weight loss than to the effect of THCV. Nor, in the absence of pharmacokinetic and concentration-response data for effects of rimonabant and THCV on GPR55- and CB1R-mediated responses in mouse tissues (such as the hypothalamus) can we attempt to explain why rimonabant caused more weight loss than THCV.

There was no effect of genotype or drug treatment on total food intake (results not shown, but are in the supplementary data file). Rimonabant raised energy expenditure significantly in the WT but not the KO mice on days 25 to 29 , but there was not a statistically significant difference between its effects in WT and KO mice (Figure 5).

Locomotor activity was measured on day 45 in the control and rimonabant-treated mice only. Neither genotype nor rimonabant had any effect on total locomotor activity or its time course (results not shown, but are in the supplementary data file).

There was no effect of genotype or treatment on lean body mass or body fat content on day 32 (Figures $6 \mathrm{~A}, 6 \mathrm{~B})$. The failure to demonstrate an effect of genotype on terminal body fat content despite the effect on body weight gain being lower in knockout mice appears to be due to the initial mean body weights (and presumably body fat contents) of the knockout mice being (non-significantly) lower than those of the corresponding wild-type groups. Body fat content was less in animals treated with THCV or rimonabant than in the control group of the same genotype, but this was not reflected in significantly reduced epididymal, inguinal of interscapular fat fad weights (Table 3).

\section{Responses to THCV and rimonabant: glucose homeostasis}

There was no effect of genotype on blood glucose after a $5 \mathrm{~h}$ fast on days 8,15 and 56 (Figures 10A, 10B and 10C). Blood glucose was lower in the THCV-treated wild-type mice on day 15 (Figure 10B) but not on days 8 or 56. At no time did rimonabant-treated wild-type mice or knockout mice treated with either THCV or rimonabant show reduced blood glucose (Figures 10A, 10B and 10C).

There was also no effect of genotype on plasma insulin on days 8, 15 and 56 (Figures 10D, 10E and 10F). On days 8 and 15 plasma insulin was lower in the THCV-treated and rimonabant-treated than in the control mice of the same genotype, although this only reached statistical significance in rimonabant-treated 
247 knockout mice on day 8 and rimonabant-treated wild-type mice on day 15. After 56 days of dosing both

248 THCV and rimonabant reduced fasting plasma insulin in wild-type mice, but neither THCV nor rimonabant 249 altered plasma insulin concentrations in GPR55 knockout mice (Figure 10F). The effects of THCV and 250 rimonabant on plasma insulin were not significantly different in wild-type or GPR55 knockout mice at any 251 time point (Figures 10G, 10H and 10I).

252 An oral glucose test was conducted on day 21. THCV $(P<0.05)$ and rimonabant $(P<0.05)$ improved 253 glucose tolerance in wild-type mice $(P<0.05$, Figure 7B). Neither THCV nor rimonabant had an overall 254 significant effect on OGTT in GPR55 knockout mice, although rimonabant did significantly lower blood 255 glucose $30 \mathrm{~min}$ after glucose load $(P<0.01)$, Figure $7 C)$. However, no genotype differences were observed 256 in the relative effects of either THCV and rimonabant after accounting for the genotype effect on glucose 257 tolerance in vehicle-treated mice (Figures 7D and 7E).

THCV - and rimonabant-treated wild-type and knockout mice had lower plasma insulin concentration 30 min before (Figure 8B) and $30 \mathrm{~min}$ after (Figure $8 \mathrm{C}$ ) a glucose load, although this only reached statistical significance in wild-type mice, although two-way ANOVA showed no interaction between the effect of treatment and genotype. Expressing the insulin concentrations relative to the respective genotype control groups also showed no significant genotype differences in the effect of either THCV or rimonabant 30 min before (Figure 8D) or 30 min after glucose load Figure 8E).

An insulin tolerance test was conducted on day 38. Blood glucose was lower in the THCV-treated wild-type mice than in the control wild-type mice both before and after administration of insulin. There was a small overall effect of rimonabant (Figure 9A). However, there was no overall effect of either drug on the fall in blood glucose after giving insulin to WT mice (Figure 9C).

The fall in blood glucose in the THCV-treated mice after giving insulin reached statistical significance in the knockout but not the THCV-treated mice (Figure 9). However, these falls did not differ significantly between the genotypes, there being no effect of genotype on the fall in blood glucose concentration with either THCV or rimonabant (see Figure 8D for absolute values).

\section{Discussion}

273 The present study addresses two broad questions: first, whether there are differences in energy balance and glucose homeostasis between wild-type and GPR55 knockout mice; second whether any effects of THCV or rimonabant differ between wild-type and GPR55 knockout mice. Our main findings are that impaired glucose tolerance in GPR55 knockout mice is restricted to mice fed on a high fat diet but is not associated with increased adiposity, and that when they are fed on a high fat diet, rimonabant and THCV have less effect on weight gain in GPR55 knockout than wild-type mice. We acknowledge that for logistical and ethical reasons, including the restriction of our UK Home Office licence, we could not conduct all 
281

282

283

284

285

286

287

288

289

290

291

292

293

294

295

296

297

298

experiments in both male and female mice, but it was not logistically possible to do this. We chose to use male mice because Meadows et al (Meadows et al., 2016), Lipina et al, (Lipina et al., 2019) and Bjursell et al (Bjursell et al, 2016) used male mice. If we had used female mice, any differences between our results and theirs could be ascribed to the use of different sexes. Despite these limitations, we believe that our results have value. Other studies have the same limitations.

\section{Phenotypic differences between wild-type and GPR55 knockout mice}

There were no differences in any aspects of energy balance (body weight, body weight change, total food consumption, daily energy expenditure, locomotor activity or body composition) between the untreated (preliminary experiment) or vehicle-treated (main experiment) wild-type and knockout mice.

Our findings differ from those of Meadows et al (Meadows et al., 2016) and Lipina et al, (Lipina et al., 2019), despite our mice being kindly supplied by one of the authors of the latter study. Both groups studied GPR55 knockout mice fed on chow but not on a high fat diet. The chow-fed GPR55 knockout mice had a higher mean body weight and fat content than wild-type mice. (Meadows et al. state that there is a numerical difference in body weight but acknowledge that it is not statistically significant.) The weights of some fat pads were also higher in the knockout mice. Lipina et al. reported that there was a significant reduction in lean body mass but this was expressed as a percentage of body weight and the consequence of increased fat mass. Meadows et al. found that genotype had no effect on food intake or resting metabolic rate, but spontaneous locomotor activity was lower in the knockout than the wild-type mice during the dark period.

Our results agree with those of Bjursell et al (Bjursell et al, 2016) in that that these investigators did not find increased body weight in the knockout mice, except for a non-significant increase in fat mass relative to body weight when the mice were fed on a 'cafeteria-fed' mice and aged 28 weeks. Our mice were killed at 15 weeks of age. These workers found increased locomotor activity in the knockout mice during the first 6 hours of the dark period although energy expenditure was not raised at this time. During the second 6 hours of the dark period, energy expenditure was no higher in their knockout than their wild-type mice and energy expenditure was depressed. We found no evidence that locomotor activity or energy expenditure was different in the knockout than the wild-type mice at any time during the dark period.

By contrast with our negative findings on energy balance, we found differences in glucose homeostasis between the untreated (preliminary experiment) or vehicle-treated (main experiment) wild-type and knockout mice in both experiments when the mice were fed on a high fat diet. The preliminary experiment found at most minor differences when the mice were fed on chow.

In both the preliminary and the main experiment, blood glucose was higher in knockout than in wild-type high fat diet-fed, untreated/vehicle-treated mice 30 and $60 \mathrm{~min}$ after giving glucose in an oral glucose tolerance test. The overall blood glucose level was also higher in the knockout mice. In both experiments, plasma insulin 30 min after giving glucose was higher in the knockout than the wild-type high fat diet-fed 
315 mice. These results suggest that insulin sensitivity was impaired in the knockout mice. Insulin tolerance 316 tests failed to back this up, however. The failure to demonstrate an effect of genotype on fasting blood glucose and plasma insulin in either the preliminary or the main experiment was also unsupportive of an effect of genotype on insulin resistance. We must therefore look beyond increased adiposity and consequent insulin resistance to account for impaired glucose tolerance in our GPR55 knockout mice.

It is feasible that impaired insulin secretion contributed to impaired glucose tolerance: plasma insulin was raised in the knockout mice after administration of glucose, but perhaps if it had been even higher glucose tolerance would have been normal. Others have reported that the GPR55 agonist O-1602 stimulated insulin secretion from wild-type but not GPR55 -/- murine islets of Langerhans (Henstridge et al., 2016; Meadows et al., 2016) and Meadows also shows $0-1602$ stimulated insulin secretion and improved glucose tolerance in vivo in rats. If impaired insulin secretion is the explanation for our findings, then it seems to be exacerbated by the high fat diet.

Other workers (Lipina et al., 2019) have reported that GPR55 knockout mice have impaired insulin sensitivity but this may be because their mice displayed increased adiposity. In fact, although they found that blood glucose fell significantly in wild-type but not knockout mice following administration of insulin, they did not find a significant difference between genotypes. They demonstrated more clearly significant differences between genotypes in insulin signalling in isolated liver, skeletal muscle and adipose tissues. By contrast with our results, the chow-fed GPR55 knockout mice of Meadows et al. (Meadows et al., 2016) showed impaired insulin tolerance, but they did not exhibit impaired glucose tolerance. Meadows et al. point to raised basal insulin and a decreased response of insulin to glucose, but they did not show that these were statistically significant differences from wild-type mice. Bjursell et al (Bjursell et al., 2016), who like us did not find increased adiposity in GPR55 knockout mice, have not reported studies on glucose homeostasis.

Some of the differences between our findings and those of Meadows et al (Meadows et al, 2016) may be due to their conducting glucose and insulin tolerance when their mice were nine months old, whereas our chow-fed mice in the preliminary study were 16- (glucose tolerance) or 20- (insulin tolerance) weeks-old. Their mice were therefore fatter and more like our high fat-fed mice. Lipina et al. conducted their measurements when the mice were 10-22 weeks old (Lipina et al, 2019).

343 Thus, our results suggest that GPR55 interacts with insulin signalling in a more direct way than via 344 increased fat mass. This mechanism merits further investigation. Despite many differences in details 345 between the findings of those who have studied GPR55 knockout mice, including ourselves, we agree that 346 GPR55 agonists might be of value in the treatment in type 2 diabetes. 
347

348

349

350

351

352

353

354

355

356

357

358

359

360

361

362

363

364

365

366

367

368

369

370

371

372

373

374

375

376

377

378

379

\section{Effects of THCV and rimonabant}

The beneficial effects of rimonabant on energy balance and glucose homeostasis in HFD-fed wild-type mice are well-known (Arch, 2011). They were reproduced in the present study.

We have previously described beneficial effects of THCV on blood glucose and plasma insulin in the fasting state and following an oral glucose load in high fat-fed obese mice (Wargent et al., 2013). Similar results were obtained in the present study in both wild-type and GPR55 knockout mice using a dose of THCV that was towards the top of the range used in the previous study. One notable difference between the studies, however, is that in the previous study (Wargent et al, 2013) THCV did not affect body weight (the same was true in ob/ob mice), whereas in the present study THCV reduced body weight, weight gain and body fat content in both the wild-type and knockout mice. This was achieved without any reduction in total food intake and neither did THCV elicit a significant increase in energy expenditure. However, there was a numerical increase in energy expenditure in the wild-type (but not the knockout) mice that did not reach statistical significance, and in increase an energy expenditure was detected in our previous study (Wargent et al, 2013). Energy expenditure was measured during days 25 to 29 only and so may not have been a reflection of the whole period of the study. Moreover, there is more variation for technical reasons in energy expenditure than in body weight and fat content and it is possible the analysis provided a false negative and it is indeed the energy expenditure that is the cause.

\section{Effect of genotype on the responses to THCV and rimonabant}

Because oral glucose tolerance is worse in GPR55 knockout mice, there may be a greater window of opportunity for THCV or rimonabant to improve metabolism in GPR55 knockout than wildtype mice. However, if the metabolic effects of THCV or rimonabant are partly mediated by GPR55, they might be less effective in GPR55 knockout than in wild-type mice.

Nor could we detect any effect of genotype on insulin tolerance. This raises the possibility that GPR55 regulates glucose-stimulated insulin secretion. A recent study found no difference between wildtype and GPR55 knockout mice murine isolated islets of Langerhans in their responses to rimonabant (RuzMaldonado et al., 2020), which is consistent with our finding that genotype did not affect the effect of rimonabant on et al glucose homeostasis. The authors did not discuss whether glucose-stimulated insulin secretion differed between islets from wild-type and knockout mice. THCV and rimonabant had less effect in the knockout than the wild-type mice, suggesting, that both compounds reduce body weight partly via GPR55. Based on the day-56 data, the effect of rimonabant on body weight gain was $33 \%$ less in the knockout than the wild-type mice $(P<0.001)$. The equivalent value for THCV was $19 \%$, but these were not significantly different effects. Moreover, although the effect of genotype on the response to THCV on day 56 was not statistically significant, it was significant on a number of previous days and over all days. 
380

381

382

383

384

385

386

387

388

389

390

391

392

393

394

395

396

397

398

399

400

401

402

403

404

405

406

407

408

7

The effects of rimonabant and THCV on body fat content could not be accounted for by differences in energy expenditure. We cannot, however, exclude the possibility that the latter measurements were insufficiently powered to detect a statistically significant effect. By contrast with our findings, Bjursell et al. (Bjursell et al., 2016) found no effect of genotype on weight loss over 14 days in response to rimonabant in cafeteria-fed mice. They did not have an untreated group and they raise the possibility that the dose they used was too low, However, it was almost the same dose that we used and so we cannot explain this difference in our findings.

\section{Conclusions}

There are varied reports on the effect of deletion of GPR55 on energy balance and glucose homeostasis in mice. Our two experiments differ from others in finding impaired glucose tolerance in GPR55 knockout mice in the absence of any effect on body weight, body composition, locomotor activity or energy expenditure. Nor could we detect any effect on insulin tolerance. The possibility that GPR55 regulates glucose-stimulated insulin secretion merits further investigation. We also found that the reduction in weight gain elicited by THCV and rimonabant were in part mediated by GPR55.

\section{Acknowledgements}

We would like to thank GW Research Ltd for their support of the work.

\section{References}

Anavi-Goffer S, Baillie G, Irving AJ, Gertsch J, Greig IR, Pertwee RG, Ross RA. (2012). Modulation of L-alysophosphatidylinositol/GPR55 mitogen-activated protein kinase (MAPK) signaling by cannabinoids. J Biol Chem. 287:91-104.

Arch JR, Hislop D, Wang SJ, Speakman JR (2006). Some mathematical and technical issues in the measurement and interpretation of open-circuit indirect calorimetry in small animals. Int J Obes 30: 132231.

Arch JRS (2011). Thermogenesis and related metabolic targets in anti-diabetic therapy. Handb Exp Pharmacol. 203:201-55.

Bjursell M, Ryberg E, Wu T, Greasley PJ, Bohlooly-Y M, Hjorth S. (2016). Deletion of Gpr55 Results in Subtle Effects on Energy Metabolism, Motor Activity and Thermal Pain Sensation. PLoS One. 11:e0167965. 
409 Festing MF, Altman DG. (2002). Guidelines for the design and statistical analysis of experiments using 410 laboratory animals. ILAR J. 43:244-58.

411 Henstridge CM, Brown AJ, Waldhoer M (2016). GPR55: Metabolic Help or Hindrance? Trends Endocrinol 412 Metab. 27:606-8. (2009).

413 Henstridge CM, Balenga NA, Schröder R, Kargl JK, Platzer W, Martini L, Arthur S, Penman J, Whistler JL, 414 Kostenis E, Waldhoer M, Irving AJ. (2010). GPR55 ligands promote receptor coupling to multiple signalling 415 pathways. Br J Pharmacol.160:604-14.

416 Kapur A, Zhao P, Sharir H, Bai Y, Caron MG, Barak LS, Abood ME. (2009). Atypical responsiveness of the 417 orphan receptor GPR55 to cannabinoid ligands. J Biol Chem. 284:29817-27.

418 Lauckner JE, Jensen JB, Chen HY, Lu HC, Hille B, Mackie K. (2008) Proc Natl Acad Sci USA 105: 26994192704

420 Lipina C, Rastedt W, Irving AJ, Hundal HS. (2012). New vistas for treatment of obesity and diabetes? 421 Endocannabinoid signalling and metabolism in the modulation of energy balance. Bioessays. 34: 681-91.

422 Lipina C, Walsh SK, Mitchell SE, Speakman JR, Wainwright CL, Hundal HS. (2019). GPR55 deficiency is 423 associated with increased adiposity and impaired insulin signaling in peripheral metabolic tissues. FASEB 424 J. 33: 1299-1312.

425 Liu B, Song S, Ruz-Maldonado I, Pingitore A, Huang GC, Baker D, Jones PM, Persaud SJ (2016). GPR55426 dependent stimulation of insulin secretion from isolated mouse and human islets of Langerhans. Diabetes 427 Obes Metab. 18: 1263-1273.

428 Meadows A, Lee JH, Wu CS, Wei Q, Pradhan G, Yafi M, Lu HC, Sun Y (2016). Deletion of G-protein429 coupled receptor 55 promotes obesity by reducing physical activity. Int J Obes (Lond). 40:417-24.

430 Moreno-Navarrete JM, Catalán V, Whyte L, Díaz-Arteaga A, Vázquez-Martínez R, Rotellar F, Guzmán R, 431 Gómez-Ambrosi J, Pulido MR, Russell WR, Imbernón M, Ross RA, Malagón MM, Dieguez C, Fernández432 Real JM, Frühbeck G, Nogueiras R. (2012). The L-a-lysophosphatidylinositol/GPR55 system and its 433 potential role in human obesity. Diabetes. 61:281-91.

434 Pearce NJ, Arch JR, Clapham JC, Coghlan MP, Corcoran SL, Lister CA, Llano A, Moore GB, Murphy GJ, 435 Smith SA, Taylor CM, Yates JW, Morrison AD, Harper AJ, Roxbee-Cox L, Abuin A, Wargent E, Holder JC. 436 (2004). Development of glucose intolerance in male transgenic mice overexpressing human glycogen 437 synthase kinase-3beta on a muscle-specific promoter. Metabolism. 53:1322-30.

438 Pertwee RG (2007). GPR55: a new member of the cannabinoid receptor clan? Br J Pharmacol. 152:9844396. 
440 Romero-Zerbo SY, Rafacho A, Díaz-Arteaga A, Suárez J, Quesada I, Imbernon M, Ross RA, Dieguez C, 441 Rodríguez de Fonseca F, Nogueiras R, Nadal A, Bermúdez-Silva FJ. (2011). A role for the putative 442 cannabinoid receptor GPR55 in the islets of Langerhans. J Endocrinol. 211:177-85.

443 Ruz-Maldonado I, Liu B, Atanes P, Pingitore A, Huang GC, Choudhary P, Persaud SJ. (2020). The 444 Cannabinoid Ligands SR141716A and AM251 Enhance Human and Mouse Islet Function via GPR55445 independent Signalling. Cell Mol Life Sci. doi: 10.1007/s00018-019-03433-6. Online ahead of print.

446 Sharir H, Abood ME (2010). Pharmacological characterization of GPR55, a putative cannabinoid receptor. 447 Pharmacol Ther. 126:301-13.

448 Wang S, Cawthorne MA, Clapham JC. (2002). Enhanced diabetogenic effect of streptozotocin in mice 449 overexpressing UCP-3 in skeletal muscle. Ann N Y Acad Sci 967:112-9.

450 Wargent ET, O'Dowd JF, Zaibi MS, Gao D, Bing C, Trayhurn P, Cawthorne MA, Arch JR, Stocker CJ (2013). 451 Contrasts between the effects of zinc- $\alpha 2-$ glycoprotein, a putative $\beta 3 / 2$-adrenoceptor agonist and the $\beta 3 / 2-$ 452 adrenoceptor agonist BRL35135 in C57BI/6 (ob/ob) mice. J Endocrinol. 216:157-68.

453 Wargent ET, Zaibi MS, Silvestri C, Hislop DC, Stocker CJ, Stott CG, Guy GW, Duncan M, Di Marzo V, 454 Cawthorne MA. (2013). The cannabinoid $\Delta(9)$-tetrahydrocannabivarin (THCV) ameliorates insulin 455 sensitivity in two mouse models of obesity. Nutr Diabetes. 3:e68

456 Whyte LS, Ryberg E, Sims NA, Ridge SA, Mackie K, Greasley PJ, Ross RA, Rogers MJ. (2009). The 457 putative cannabinoid receptor GPR55 affects osteoclast function in vitro and bone mass in vivo. Proc Natl 458 Acad Sci U S A. 106:16511-6.

459

460 Table and Figure Legends

461

462

463

464

465

466

467

468

469

470

Table 1: Body composition, energy balance and locomotor activity in chow-fed mice in preliminary experiment.

Food intake was measured daily when the mice were between 15 and 20 weeks of age, body composition and energy expenditure when they were 16 weeks old, and locomotor activity when they were 17 weeks old. Fat pad weights were measured at termination (20 weeks old). Energy expenditure was measured over $22 \mathrm{~h}$ beginning at 14:00 $\mathrm{h}$. Locomotor activity was measured from 19:00 to 08:00 $\mathrm{h}$. Lights were out from 20:00 to 08:00 h. Where $n=6$, measurements were recorded for pairs of mice and divided by two. Values of $n$ were the same for wild-type and GPR55 knockout mice. Results are shown as the mean \pm SEM. Student's $t$ test returned no statistically significant differences between wild-type and knockout mice. The lowest value of $P$ was 0.08 for epididymal fat pad weights. Other values were $>0.25$.

Peer] reviewing PDF | (2020:04:47549:2:0:NEW 3 Aug 2020) 
471

473

474

475

476

477

478

479

480

481

482

483

484

485

486

487

488

489

490

491

492

493

494

495

496

497

498

499

500

501

502

503

504

Table 2: Body composition, energy balance and locomotor activity in high fat-fed mice in preliminary experiment.

Food intake was measured daily when the mice were between 6 and 15 weeks of age, body composition by DEXA and NMR when they were 14 and 15 weeks old respectively, energy expenditure when they were 10 to 11 weeks old, and locomotor activity when they were 13 weeks old. Fat pad weights were measured at termination (15 weeks old). Energy expenditure was measured over $21 \mathrm{~h}$ beginning at 14:00 $\mathrm{h}$. Locomotor activity was measured from 19:00 to 08:00 h. Lights were out from 20:00 to 08:00 h. Where $\mathrm{n}=$ 6 measurements were recorded for pairs of mice and divided by two, except for the knockout mice that was housed singly. Results are shown as the mean \pm SEM. There were no statistically significant differences between wild-type and knockout mice by Student's $t$ test. The lowest value of $P$ was 0.053 for interscapular fat pad weights. Other values were $>0.1$.

\section{Table 3: Fad pad weights and locomotor activity in the main experiment.}

Fat pad weights were measured at termination on day 56. Locomotor activity $(n=4)$ was measured for pairs of mice from 19:00 on day 43 to $08: 00 \mathrm{~h}$ on day 44 when the mice were 22 weeks old and had been fed on the high fat diet for 16 weeks. Line break are given per mouse. Lights were out from 20:00 to 08:00 h. The locomotor activity was not measured for the THCV-treated mice. Results are shown as the mean \pm SEM. Two-way ANOVA showed no significant effects of treatment or genotype on either fat pad weights or locomotor activity.

Figure 1. Growth trajectory in GPR55 knockout and wild-type mice.. Bodyweight are shown for GPR55 knockout and control mice fed on chow (A), and high fat diet (B). Body weight change is shown for mice fed chow (C) or high fat diet (D). Results are shown as the mean \pm SEM. Two-way ANOVA showed no statistically significant differences between wild-type and knockout mice.

Figure 2. Glucose and insulin tolerance in GPR55 knockout and wild-type mice fed on a standard chow diet. Blood glucose concentration $(A)$ and plasma insulin $(B)$ before and after a glucose load $(t=0$ $\mathrm{min}$ ) at age 16 weeks after a 5 hour fast, and blood glucose concentration expressed as absolute values (C) or change from $t=0 \mathrm{~min}(\mathrm{D})$ following an insulin load $(\mathrm{t}=0 \mathrm{~min}$ ) at age 20 weeks after a 5 hour fast. Results are shown as the mean \pm SEM. Two-way ANOVA showed no effect of genotype on blood glucose in the tolerance test. There was no statistically significant difference by two-way ANOVA in plasma insulin at $t=-30$ or $t=+30$ in the OGTT. Nor was there any difference between genotypes in blood glucose levels following an insulin load.

Figure 3. Glucose and insulin tolerance in GPR55 knockout and wild-type mice fed on a high fat diet. Blood glucose concentration (A) and plasma insulin (B) before and after a glucose load $(t=0 \mathrm{~min})$ at age 13 weeks after a 5 hour fast, and blood glucose concentration expressed as absolute values (C) or change from $t=0 \mathrm{~min}(D)$ following an insulin load $(t=0 \mathrm{~min})$ at age 14 weeks after a 5 hour fast. Two-way

Peer) reviewing PDF | (2020:04:47549:2:0:NEW 3 Aug 2020) 
505

506

507

508

509

510

511

512

513

514

515

516

517

518

519

520

521

522

523

524

525

526

527

528

529

530

531

532

533

534

535

536

537

ANOVA with time-matching followed by the FDR test showed that blood glucose was higher in the knockout mice at 30 and 60 min after dosing with glucose. Results are shown as the mean \pm SEM. Two-way ANOVA followed by the FDR test showed plasma insulin was higher in the knockout mice 30 after glucose. Twoway ANOVA followed by the FDR test showed higher blood glucose levels in the knockouts 20 min to 60 min following an insulin load. There was no genotype effect on the change in blood glucose following an insulin load. $\star \star P<0.01$.

Figure 4. Bodyweight gain of GPR55 knockout and wild-type mice fed on a high fat diet and dosed with vehicle only (A), THCV (B) or rimonabant (C). Vehicle only values are shown in all panels to facilitate comparisons of the effects of genotypes and drugs. Results are shown as the mean \pm SEM. Two-way ANOVA followed by the FDR test showed an overall effect of genotype on body weight gain in response to both THCV (B) and rimonabant (C).

Figure 5. 24-hour energy expenditure in mice fed on a high-fat diet and dosed with vehicle, THCV or rimonabant.. Energy expenditure measurements were performed on days 25-29 of dosing. Results are shown as the mean \pm SEM. Two-way ANOVA followed by the FDR test showed that expenditure elicited by. rimonabant significantly increased energy expenditure in wild-type mice. It did not increase energy expenditure significantly in knockout mice, but there was not a significant difference between energy expenditure in rimonabant-dosed wild-type mice and rimonabant-dosed knockout mice. $\star \star P<0.01$.

Figure 6. Lean and fat mass of GPR55 knockout and wild-type mice fed on a high fat diet and dosed with vehicle, THCV or rimonabant. Body composition was measured by NMR on day 32. Results are shown as the mean \pm SEM. Two-way ANOVA followed by the FDR test showed no effect of either rimonabant or THCV on lean mass in either wild type or knockout mice (A). There was a significant effect of either THCV or rimonabant on fat mass in both wild-type and knockout mice (B). Genotype had no effect on the extent of fat mass reduction elicited by either THCV or rimonabant. $\star P<0.05 ; \star \star P<0.01$; $\star \star \star \star P<0.0001$.

Figure 7. Glucose tolerance in GPR55 knockout and control mice on a high fat diet and treated with THCV or rimonabant.. Blood glucose concentrations during an oral glucose tolerance test on day 21 are expressed as wild-type vs knockout mice (A), THCV and rimonabant-treated wild-type and knockout mice as absolute values ( $B$ and $C$ ) and relative to the respective control group in wild-type (D) and knockout mice (E). Results are shown as the mean \pm SEM. Two-way ANOVA followed by the FDR test showed that both THCV and rimonabant improved glucose tolerance in wildtype mice. Neither THCV nor rimonabant had an overall significant effect on glucose tolerance in GPR55 knockout mice, although rimonabant lowered blood glucose $30 \mathrm{~min}$ after glucose load. No genotype differences were observed in the relative effects of either THCV or rimonabant. $\star P<0.05 ; \star \star \dagger \dagger P<0.01 ; \star \star \star \dagger \dagger P<0.001$ 
538 Figure 8. Plasma insulin concentrations during a glucose tolerance in GPR55 knockout and wild539 type mice fed on a high fat diet and treated with vehicle, THCV or rimonabant. Plasma insulin

540

541

542

543

544

545

546

547

548

549

550

551

552

553

554

555

556

557

558

559

560

561

562

563

564

565

566

567

568

569

570

571

572 concentrations in the oral glucose tolerance test on day 21. For clarity, the absolute values for the untreated mice are reproduced in panel $A$, and the significance in panel $A$ is not repeated in panel $C$. Panels $B$ and $C$ only show significance relative to the relevant wild-type or knockout control mice. Knockout mice had significantly higher by two-way ANOVA plasma insulin levels $30 \mathrm{~min}$ following an oral glucose load (A). Plasma insulin levels for THCV- and rimonabant-treated are shown $30 \mathrm{~min}$ before (B [absolute values] and $\mathrm{D}$ [relative to control group]) and after ( $\mathrm{C}$ [absolute values] and $\mathrm{E}$ [relative to control group]) a glucose load. Results are shown as the mean \pm SEM. Two-way ANOVA followed by the FDR test showed that both THCV- and rimonabant-dosed mice had lower plasma insulin 30 before and 30 after glucose. However, the relative effects of THCV and rimonabant were not significantly different between wild-type and knockout mice. $\star P<0.05$.

Figure 9. Blood glucose concentrations during an insulin tolerance test in GPR55 knockout and wild-type mice fed on a high fat diet and treated with THCV or rimonabant. Results are shown as the mean \pm SEM. In an insulin tolerance test on day 38, two-way ANOVA followed by the FDR test showed that blood glucose was lower in the THCV-treated wild-type mice before and after administration of insulin (A). There was a small non-significant overall effect of rimonabant (A). However, there was no overall effect of either drug on the fall in blood glucose after giving insulin to WT mice (C). The fall in blood glucose after giving insulin to the knockout mice reached statistical significance in the THCV-treated mice (Figures B, D) but there was no effect of genotype on the fall in blood glucose concentration in the control or the drugtreated mice (see Figure 8D for absolute values). $\star \dagger P<0.05 ; \uparrow \dagger P<0.01 ; \uparrow \dagger \uparrow P<0.001$

Fig. 10. Blood glucose and plasma insulin concentrations in GPR55 knockout and wild-type mice fed on a high fat diet and treated with THCV or rimonabant. Results are shown as the mean \pm SEM. Two-way ANOVA followed by the FDR test showed no effect of genotype on blood glucose after a $5 \mathrm{~h}$ fast on days 8,15 and 56 (Figures A, B and C). On both days 8 and 15, blood glucose was lower in the THCVtreated and rimonabant-treated wild-type mice than in the control wild-type mice. Blood glucose was also lower in the rimonabant-treated knockout mice than in the control knockout mice. There was no effect of genotype on plasma insulin on days 8, 15 and 56 (Figures D, E and F). On days 8 and 15 plasma insulin was lower in the THCV-treated and rimonabant-treated than in the control mice of the same genotype, although this only reached statistical significance in rimonabant-treated knockout mice on day 8 and rimonabant-treated wild-type mice on day 15. After 56 days of dosing both THCV and rimonabant reduced fasting plasma insulin in wild-type mice, but neither THCV nor rimonabant altered plasma insulin concentrations in GPR55 knockout mice (Figure F). The effects of THCV and rimonabant on plasma insulin were not significantly different in wild-type or GPR55 knockout mice at any time point (Figures G, H and I). $\star P<0.05 ; \star \star P<0.01$. 


\section{Table $\mathbf{1}$ (on next page)}

Body composition, energy balance and locomotor activity in chow-fed mice in preliminary experiment.

Bodyweight are shown for GPR55 knockout and control mice fed on chow (A), and high fat diet (B). Body weight change is shown for mice fed chow (C) or high fat diet (D). Two-way ANOVA showed no statistically significant differences between wild-type and knockout mice. 


\begin{tabular}{|c|c|c|c|}
\hline & $\mathbf{n}$ & Wild-type mice & Knockout mice \\
\hline Body fat content (g) & 12 & $13.01 \pm 0.57$ & $13.13 \pm 0.54$ \\
\hline Body lean content (g) & 12 & $18.02 \pm 0.68$ & $18.63 \pm 0.85$ \\
\hline Epididymal fat pads (g) & 12 & $1.09 \pm 0.09$ & $0.85 \pm 0.10$ \\
\hline Inguinal fat pads (g) & 12 & $0.60 \pm 0.06$ & $0.52 \pm 0.07$ \\
\hline Interscapular fat pads (g) & 12 & $0.108 \pm 0.007$ & $0.118 \pm 0.013$ \\
\hline Food intake over 35 days (g) & 6 & $111 \pm 2$ & $3.38 \pm 0.21$ \\
\hline Energy expenditure (kJ/h) & 6 & $3.17 \pm 0.13$ & $28.8 \pm 1.79$ \\
\hline Activity (Line breaks per 10 $\mathbf{~ m i n ) ~}$ & 6 & $31.3 \pm 1.2$ & \\
\hline
\end{tabular}

2

3 


\section{Table 2 (on next page)}

Body composition, energy balance and locomotor activity in high fat-fed mice in preliminary experiment.

Food intake was measured daily when the mice were between 6 and 15 weeks of age, body composition by DEXA and NMR when they were 14 and 15 weeks old respectively, energy expenditure when they were 10 to 11 weeks old, and locomotor activity when they were 13 weeks old. Fat pad weights were measured at termination (15 weeks old). Energy expenditure was measured over $21 \mathrm{~h}$ beginning at 14:00 $\mathrm{h}$. Locomotor activity was measured from 19:00 to 08:00 h. Lights were out from 20:00 to 08:00 h. Where $n=6$ measurements were recorded for pairs of mice and divided by two, except for the knockout mice that was housed singly. There were no statistically significant differences between wild-type and knockout mice by Student's t test. The lowest value of $P$ was 0.053 for interscapular fat pad weights. Other values were $>0.1$. 


\begin{tabular}{|c|c|c|c|}
\hline & $\mathbf{n}$ & $\begin{array}{c}\text { Wild-type mice } \\
(\mathbf{n = 1 2 / 6 )}\end{array}$ & $\begin{array}{c}\text { Knockout mice } \\
(\mathbf{n = 1 2 / 6 )}\end{array}$ \\
\hline Body fat content by DEXA (g) & $12 / 11$ & $21.75 \pm 0.48$ & $23.24 \pm 0.80$ \\
\hline Body lean content by DEXA (g) & $12 / 11$ & $19.37 \pm 0.71$ & $17.91 \pm 0.92$ \\
\hline Bone mineral density (g/cm $\left.\mathbf{~}^{\mathbf{3}}\right)$ & $12 / 11$ & $0.0531 \pm 0.0007$ & $0.0518 \pm 0.0013$ \\
\hline Body fat content by NMR (g) & $12 / 11$ & $22.89 \pm 0.68$ & $23.17 \pm 0.81$ \\
\hline Body lean content by NMR (g) & $12 / 11$ & $18.18 \pm 0.43$ & $18.33 \pm 0.85$ \\
\hline Epididymal fat pads (g) & $12 / 11$ & $2.18 \pm 0.09$ & $2.05 \pm 0.09$ \\
\hline Inguinal fat pads (g) & $12 / 11$ & $1.712 \pm 0.126$ & $1.513 \pm 0.07$ \\
\hline Interscapular fat pads (g) & $12 / 11$ & $0.108 \pm 0.007$ & $0.118 \pm 0.133$ \\
\hline Food intake over 62 days (g) & 6 & $166 \pm 6$ & $171 \pm 5$ \\
\hline Energy expenditure (kJ/h) & 6 & $3.52 \pm 0.12$ & $3.81 \pm 0.25$ \\
\hline Activity (Line breaks per $\mathbf{1 0}$ min) & 6 & $26.6 \pm 4.5$ & $20.96 \pm 5.79$ \\
\hline
\end{tabular}




\section{Table 3 (on next page)}

Fad pad weights and locomotor activity in the main experiment.

Fat pad weights were measured at termination on day 56. Locomotor activity $(n=4)$ was measured for pairs of mice from 19:00 on day 43 to 08:00 h on day 44 when the mice were 22 weeks old and had been fed on the high fat diet for 16 weeks. Line break are given per mouse. Lights were out from 20:00 to 08:00 h. The locomotor activity was not measured for the THCV-treated mice. One-way ANOVA showed no significant effects of treatment or genotype on either fat pad weights or locomotor activity. 


\begin{tabular}{|c|c|c|c|c|c|c|}
\hline & \multicolumn{3}{|c|}{ Wild-type mice } & \multicolumn{3}{|c|}{ Knockout mice } \\
\hline & Control & THCV & Rimonabant & Control & THCV & Rimonabant \\
\hline $\begin{array}{l}\text { n for fat pad } \\
\text { weights }\end{array}$ & 11 & 12 & 11 & 12 & 10 & 12 \\
\hline $\begin{array}{l}\text { Epididymal fat } \\
\text { pads }(\mathrm{g})\end{array}$ & $\begin{array}{l}1.19 \pm \\
0.07\end{array}$ & $\begin{array}{c}1.16 \pm \\
0.09\end{array}$ & $1.13 \pm 0.09$ & $\begin{array}{c}1.29 \pm \\
0.09\end{array}$ & $\begin{array}{l}1.19 \pm \\
0.04\end{array}$ & $1.10 \pm 0.05$ \\
\hline $\begin{array}{l}\text { Inguinal fat pads } \\
\text { (g) }\end{array}$ & $\begin{array}{c}1.10 \pm \\
0.15\end{array}$ & $\begin{array}{c}1.01 \pm \\
0.08\end{array}$ & $0.97 \pm 0.10$ & $\begin{array}{c}1.06 \pm \\
0.12\end{array}$ & $\begin{array}{c}1.04 \pm \\
0.13\end{array}$ & $0.86 \pm 0.09$ \\
\hline $\begin{array}{l}\text { Interscapular fat } \\
\text { pads (g) }\end{array}$ & $\begin{array}{c}0.295 \pm \\
0.035 \\
\end{array}$ & $\begin{array}{c}0.380 \pm \\
0.076\end{array}$ & $0.286 \pm 0.033$ & $\begin{array}{c}0.307 \pm \\
0.028 \\
\end{array}$ & $\begin{array}{c}0.273 \pm \\
0.031 \\
\end{array}$ & $\begin{array}{c}0.217 \pm \\
0.027 \\
\end{array}$ \\
\hline $\begin{array}{lr}\text { Activity } & \text { (Line } \\
\text { breaks per } 10 \\
\text { min) }\end{array}$ & $23.3 \pm 0.7$ & - & $21.5 \pm 0.2$ & $24.2 \pm 0.5$ & - & $22.0 \pm 1.2$ \\
\hline
\end{tabular}

2 
Figure 1

Growth trajectory in GPR55 knockout and wild-type mice

Bodyweight are shown for GPR55 knockout and control mice fed on chow (A), and high fat diet (B). Body weight change is shown for mice fed chow (C) or high fat diet (D). Two-way ANOVA showed no statistically significant differences between wild-type and knockout mice.
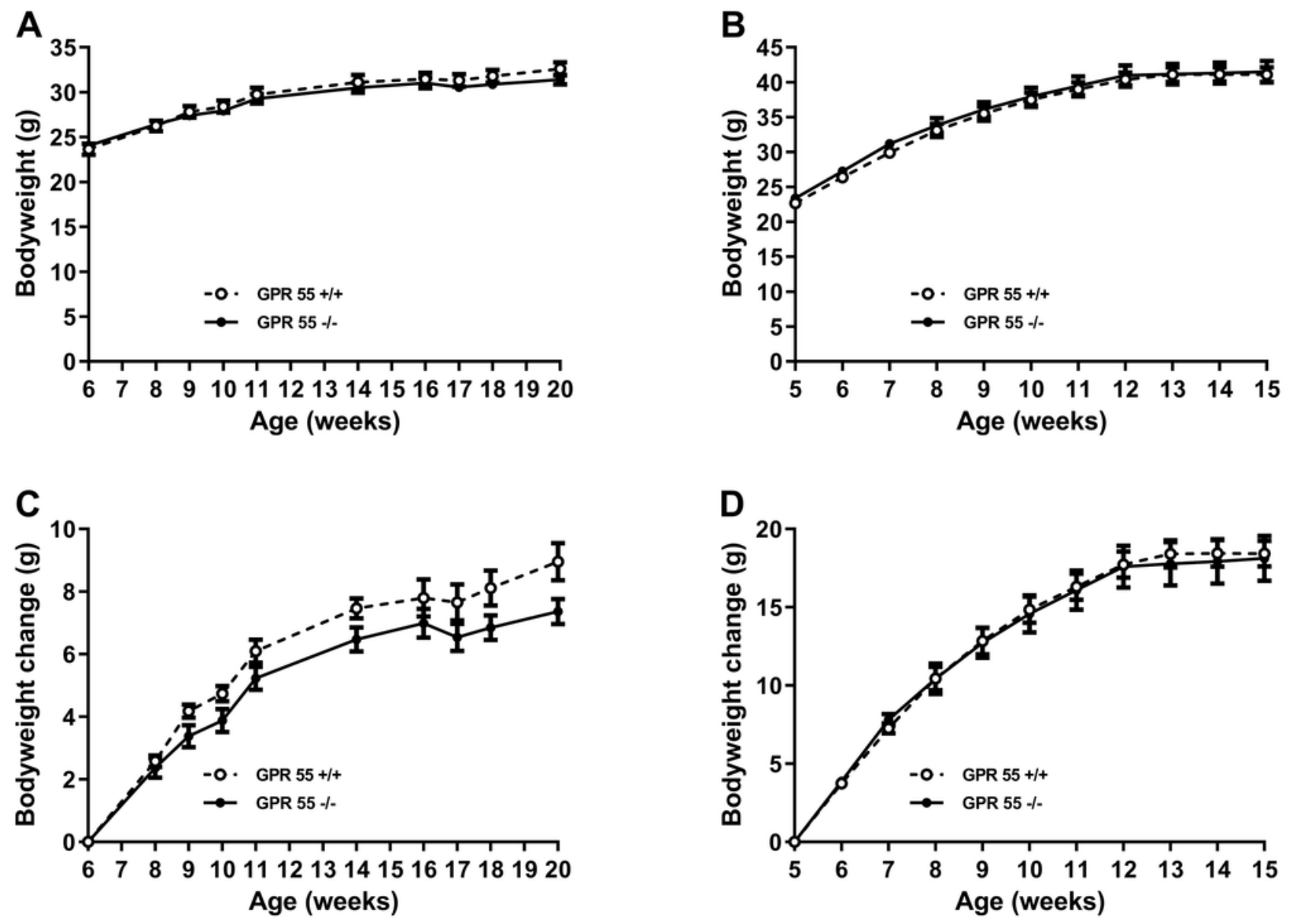


\section{Figure 2}

Glucose and insulin tolerance in GPR55 knockout and wild-type mice fed on a standard chow diet

Blood glucose concentration ( $\mathrm{A}$ ) and plasma insulin (B) before and after a glucose load ( $\mathrm{t}=0$ $\mathrm{min}$ ) at age 16 weeks after a 5 hour fast, and blood glucose concentration expressed as absolute values (C) or change from $t=0 \mathrm{~min}(\mathrm{D})$ following an insulin load ( $t=0 \mathrm{~min}$ ) at age 20 weeks after a 5 hour fast. Two-way ANOVA showed no effect of genotype on blood glucose in the tolerance test, although Fisher's LSD test suggested that blood glucose was higher in the knockout mice at $60 \mathrm{~min}(P<0.05)$. There was no statistically significant difference by two-way ANOVA in plasma insulin at $\mathrm{t}=-30$ or $\mathrm{t}=+30$ in the OGTT. Nor was there any difference between genotypes in blood glucose levels following an insulin load. 

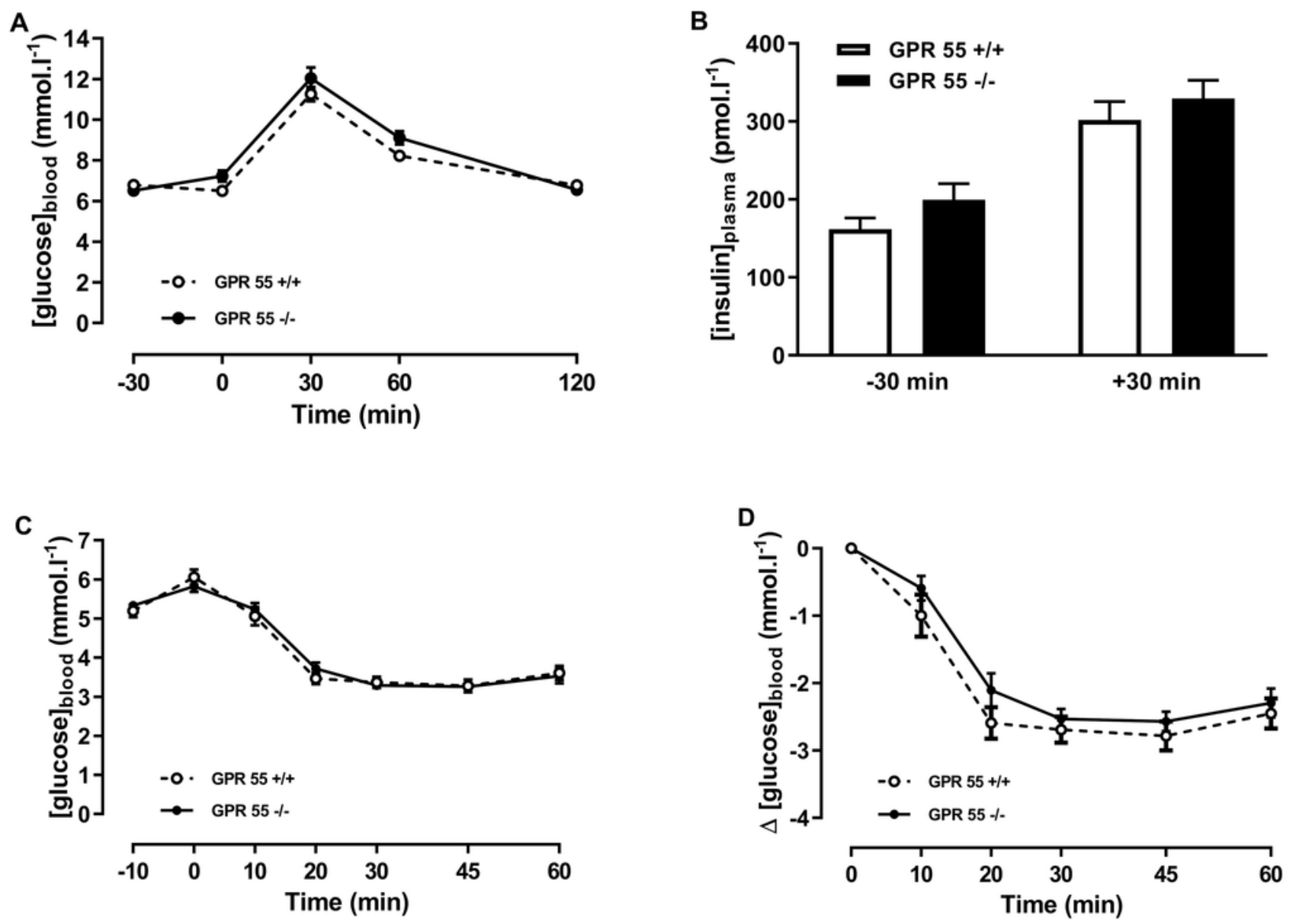


\section{Figure 3}

Glucose and insulin tolerance in GPR55 knockout and wild-type mice fed on a high fat diet.

Blood glucose concentration ( $\mathrm{A}$ ) and plasma insulin (B) before and after a glucose load ( $\mathrm{t}=0$ $\mathrm{min}$ ) at age 13 weeks after a 5 hour fast, and blood glucose concentration expressed as absolute values (C) or change from $t=0 \mathrm{~min}(\mathrm{D})$ following an insulin load ( $t=0 \mathrm{~min}$ ) at age 14 weeks after a 5 hour fast. Two-way ANOVA with time-matching followed by the FDR test showed that blood glucose was higher in the knockout mice at 30 and 60 min after dosing with glucose. Two-way ANOVA followed by the FDR test showed plasma insulin was higher in the knockout mice 30 after glucose. Two-way ANOVA followed by the FDR test showed higher blood glucose levels in the knockouts $20 \mathrm{~min}$ to $60 \mathrm{~min}$ following an insulin load. There was no genotype effect on the change in blood glucose following an insulin load. ${ }^{*} P<0.01$. 

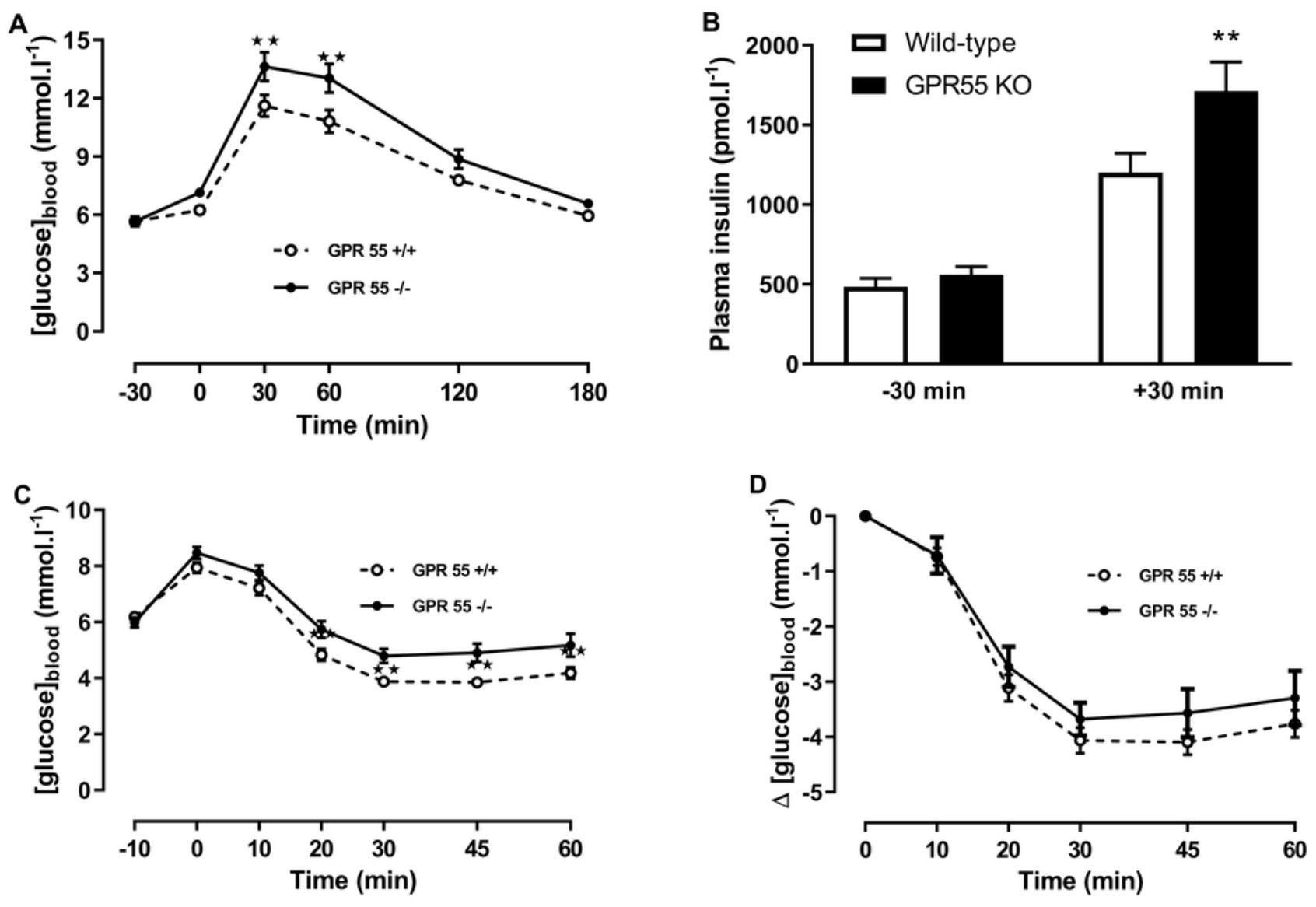
Figure 4

Bodyweight gain of GPR55 knockout and wild-type mice fed on a high fat diet and dosed with vehicle only $(A)$, THCV $(B)$ or rimonabant $(C)$.

Vehicle only values are shown in all panels to facilitate comparisons of the effects of genotypes and drugs. Two-way ANOVA followed by the FDR test showed an overall effect of genotype on body weight gain in response to both THCV (B) and rimonabant (C). * P , 0.05, ** $\mathrm{P}<0.01, * * * * \mathrm{P}<0.0001$.

A

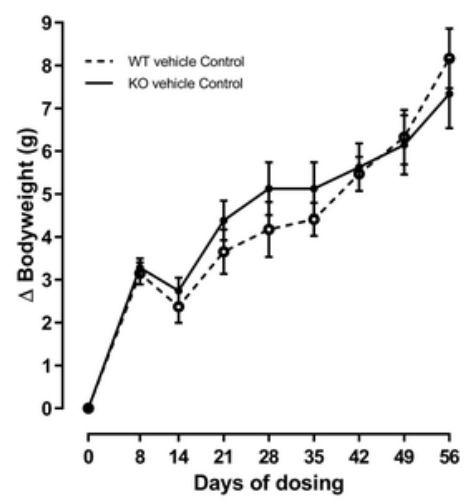

B

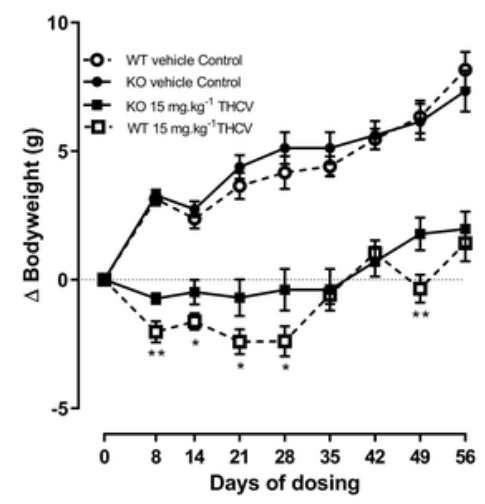

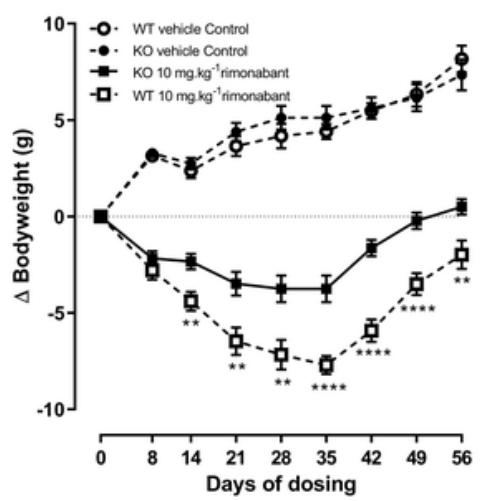




\section{Figure 5}

24-hour energy expenditure in mice fed on a high-fat diet and dosed with vehicle, THCV or rimonabant

Energy expenditure measurements were performed on days 25-29 of dosing. Two-way ANOVA followed by the FDR test showed that rimonabant significantly increased energy expenditure in wild-type mice. It did not increase energy expenditure significantly in knockout mice, but there was not a significant difference between energy expenditure in rimonabant-dosed wild-type mice and rimonabant-dosed knockout mice. ${ }^{* *} P<0.01$. 


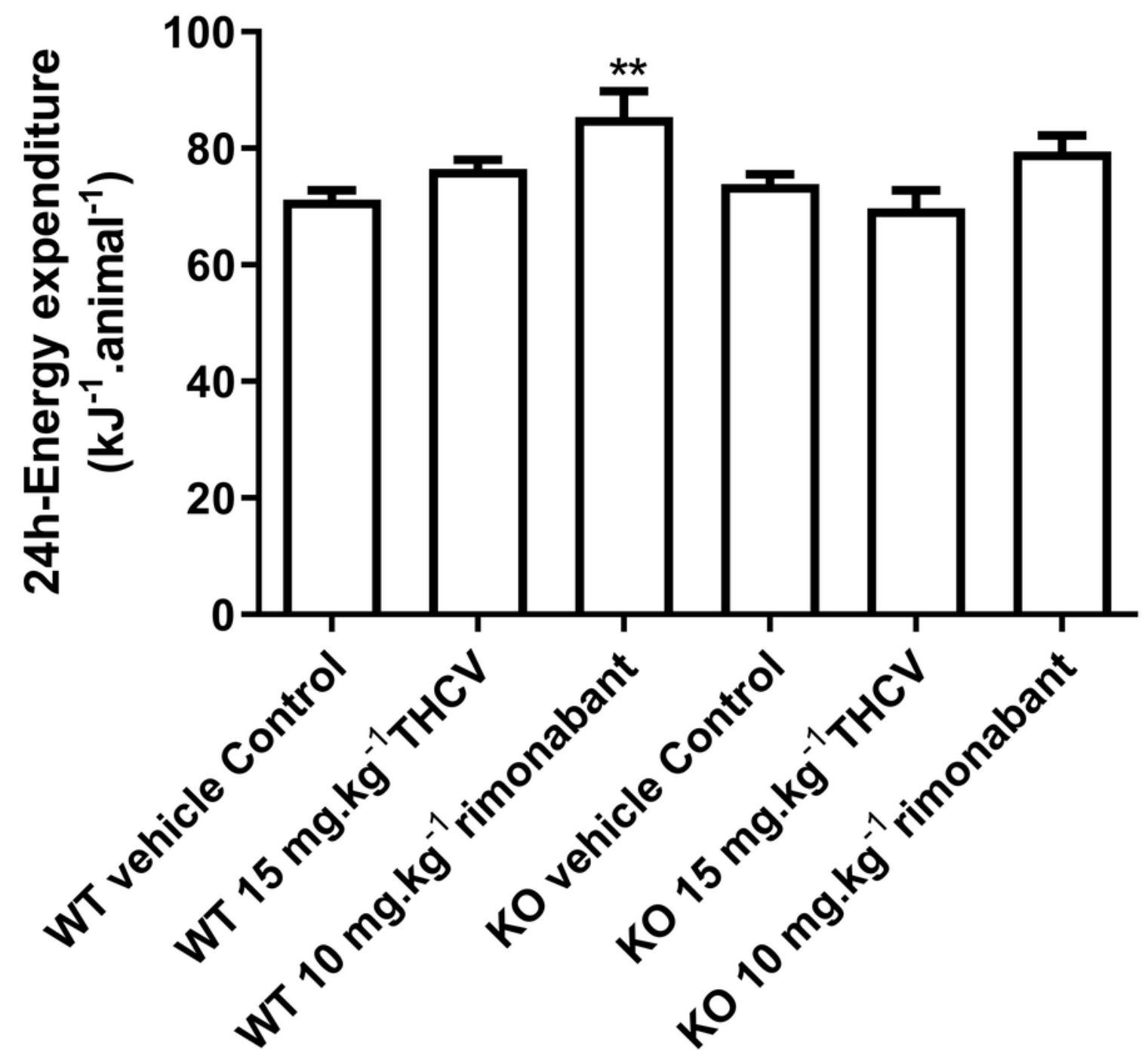


Figure 6

Lean and fat mass of GPR55 knockout and wild-type mice fed on a high fat diet and dosed with vehicle, THCV or rimonabant.

Body composition was measured by NMR on day 32. Two-way ANOVA followed by the FDR test showed no effect of either rimonabant or THCV on lean mass in either wild type or knockout mice (A). There was a significant effect of either THCV or rimonabant on fat mass in both wild-type and knockout mice (B). Genotype had no effect on the extent of fat mass reduction elicited by either THCV or rimonabant. $* P<0.05 ; * * P<0.01 ; * * * P<0.0001$.

A

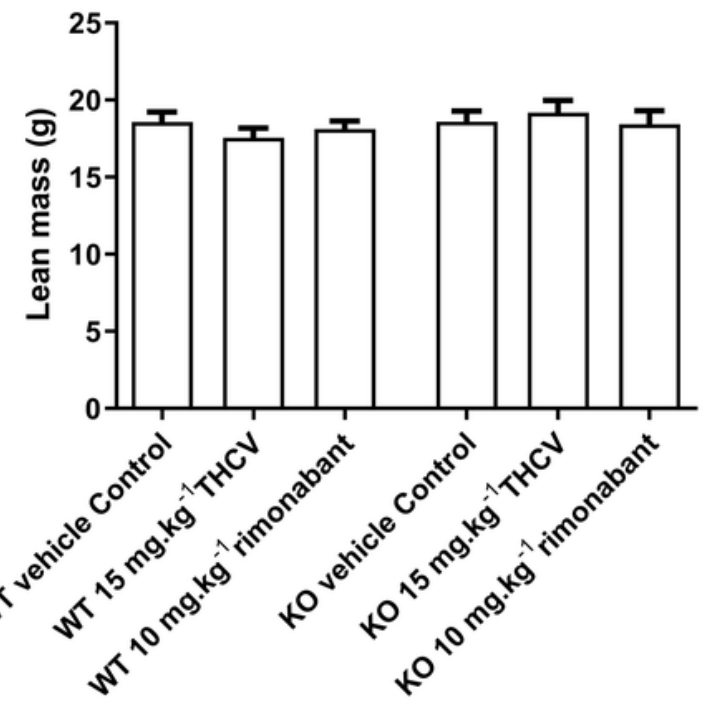

B

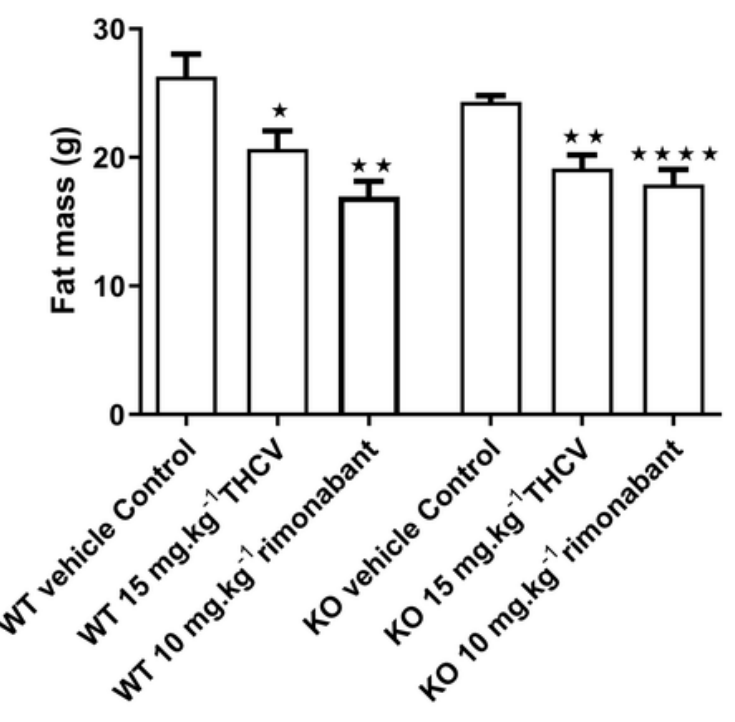




\section{Figure 7}

Glucose tolerance in GPR55 knockout and control mice on a high fat diet and treated with THCV or rimonabant

Blood glucose concentrations during an oral glucose tolerance test on day 21 are expressed as wild-type vs knockout mice (A), THCV and rimonabant-treated wild-type and knockout mice as absolute values ( $B$ and $C$ ) and relative to the respective control group in wild-type (D) and knockout mice (E). Two-way ANOVA followed by the FDR test showed that both THCV and rimonabant improved glucose tolerance in wildtype mice. Neither THCV nor rimonabant had an overall significant effect on glucose tolerance in GPR55 knockout mice, although rimonabant lowered blood glucose $30 \mathrm{~min}$ after glucose load. No genotype differences were observed in the relative effects of either THCV or rimonabant. $* P<0.05$; ${ }^{*}++P<0.01$; $* * *++\uparrow<0.001$ 
A

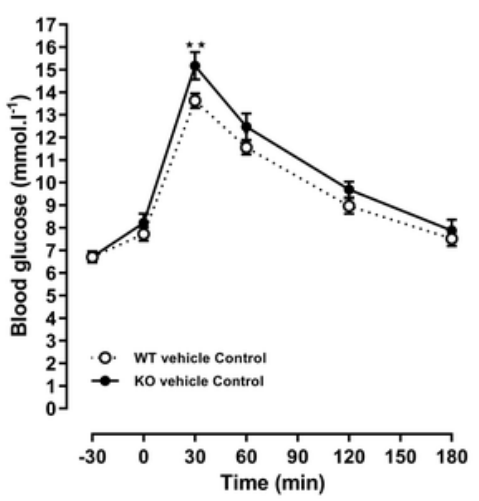

B

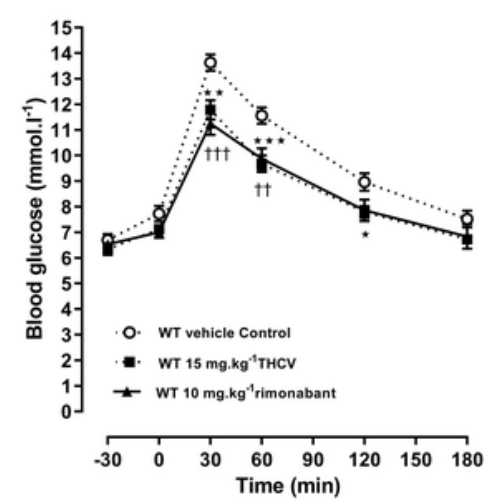

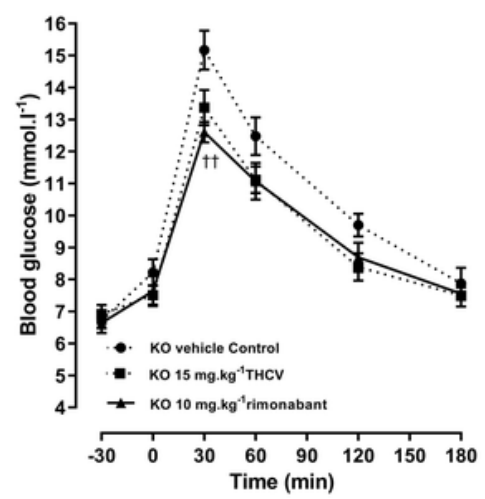

D

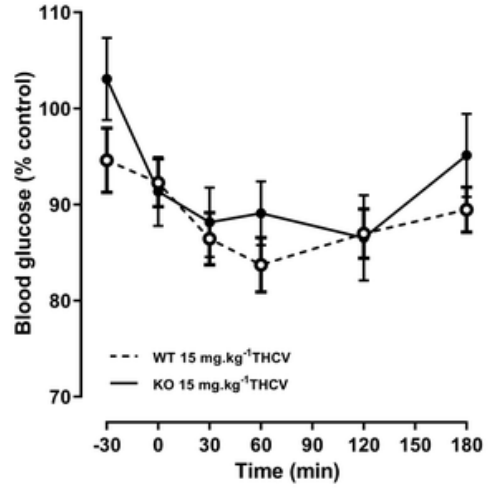

E

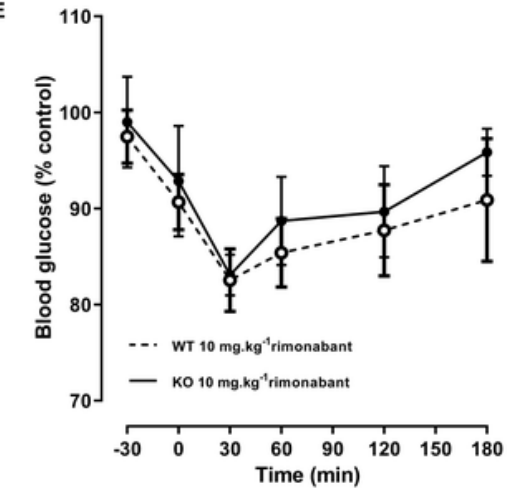




\section{Figure 8}

Plasma insulin concentrations during a glucose tolerance in GPR55 knockout and wildtype mice fed on a high fat diet and treated with vehicle, THCV or rimonabant.

Plasma insulin concentrations in the oral glucose tolerance test on day 21. Knockout mice had significantly higher by two-way ANOVA plasma insulin levels 30 min following an oral glucose load (A). Plasma insulin levels for THCV- and rimonabant-treated are shown $30 \mathrm{~min}$ before (B [absolute values] and D [relative to control group]) and after (C [absolute values] and $E$ [relative to control group]) a glucose load. Two-way ANOVA followed by the FDR test showed that both THCV- and rimonabant-dosed mice had lower plasma insulin 30 before and 30 after glucose. However, the relative effects of THCV and rimonabant were not significantly different between wild-type and knockout mice. ${ }^{*} P<0.05$.

A

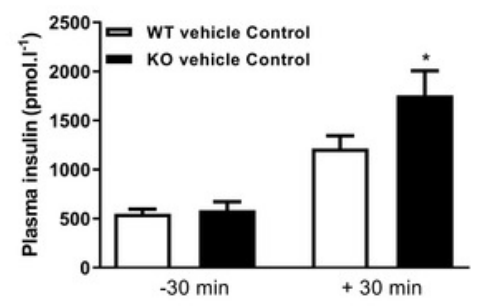

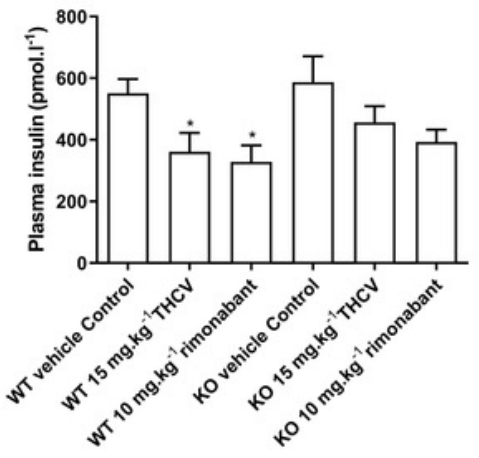

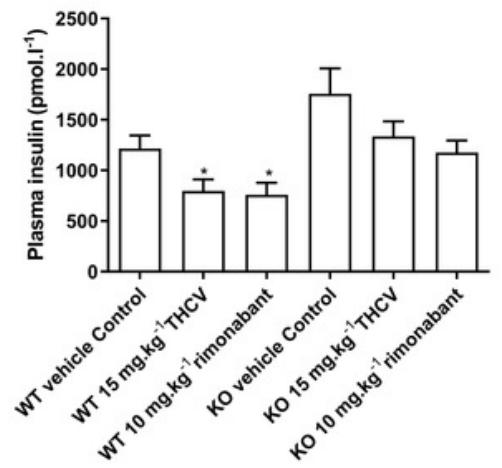

D

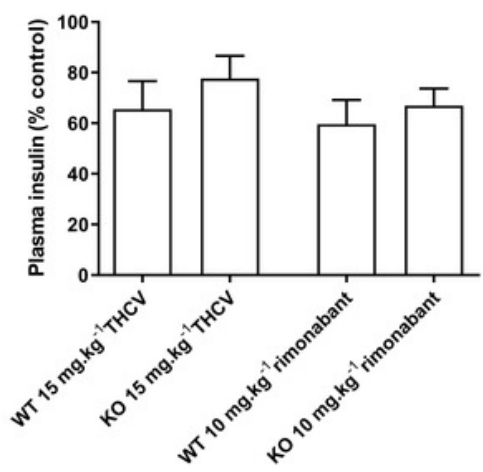

E

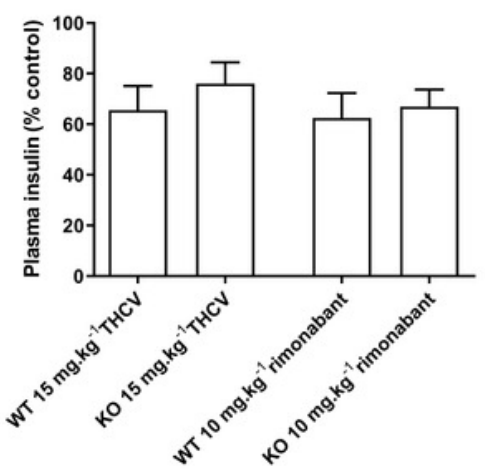




\section{Figure 9}

Blood glucose concentrations during an insulin tolerance test in GPR55 knockout and wild-type mice fed on a high fat diet and treated with THCV or rimonabant.

In an insulin tolerance test on day 38, two-way ANOVA followed by the FDR test showed that blood glucose was lower in the THCV-treated wild-type mice before and after administration of insulin (A). There was a small non-significant overall effect of rimonabant (A). However, there was no overall effect of either drug on the fall in blood glucose after giving insulin to WT mice (C). The fall in blood glucose after giving insulin to the knockout mice reached statistical significance in the THCV-treated mice (Figures B, D) but there was no effect of genotype on the fall in blood glucose concentration with any treatment (see Figure 8D for absolute values). ${ }^{*}+P<0.05 ; \dagger+P<0.01 ; \dagger+\uparrow P<0.001$ 
A

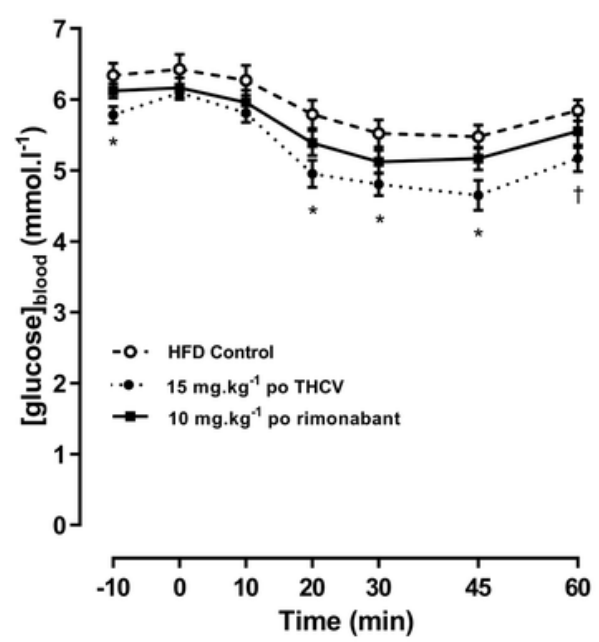

C

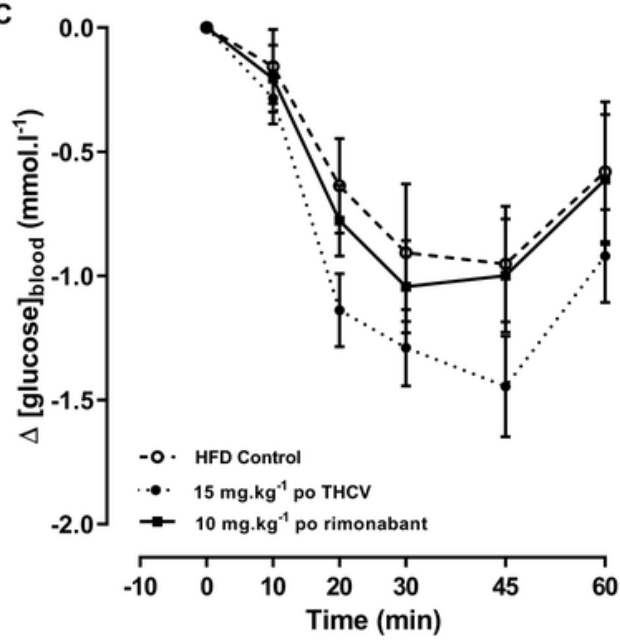

B

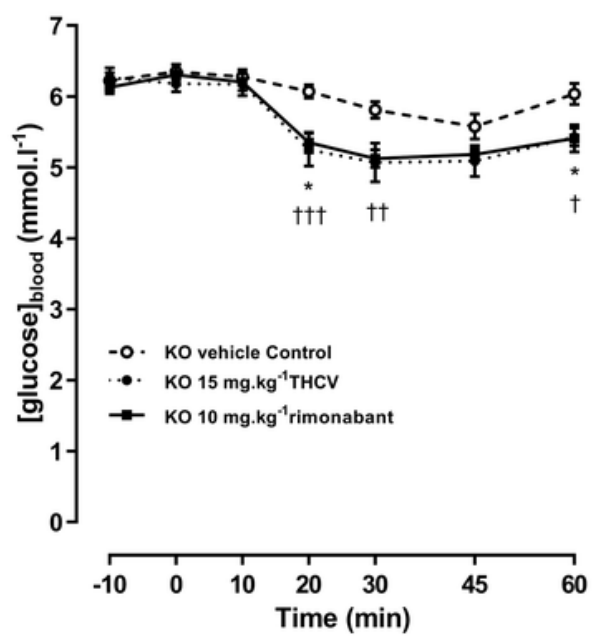

D

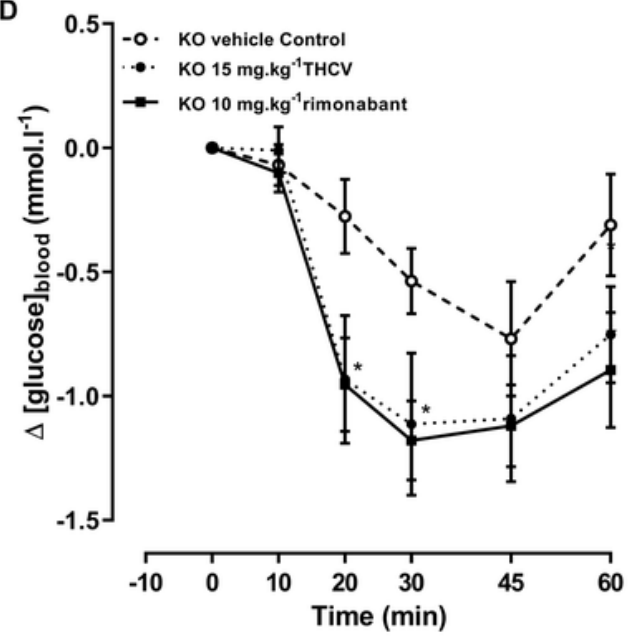




\section{Figure 10}

Blood glucose and plasma insulin concentrations in GPR55 knockout and wild-type mice fed on a high fat diet and treated with THCV or rimonabant

Two-way ANOVA followed by the FDR test showed no effect of genotype on blood glucose after a $5 \mathrm{~h}$ fast on days 8,15 and 56 (Figures A, B and C). On both days 8 and 15, blood glucose was lower in the THCV-treated and rimonabant-treated wild-type mice than in the control wild-type mice. Blood glucose was also lower in the rimonabant-treated knockout mice than in the control knockout mice. There was no effect of genotype on plasma insulin on days 8,15 and 56 (Figures D, E and F). On days 8 and 15 plasma insulin was lower in the THCV-treated and rimonabant-treated than in the control mice of the same genotype, although this only reached statistical significance in rimonabant-treated knockout mice on day 8 and rimonabant-treated wild-type mice on day 15. After 56 days of dosing both THCV and rimonabant reduced fasting plasma insulin in wild-type mice, but neither THCV nor rimonabant altered plasma insulin concentrations in GPR55 knockout mice (Figure F). The effects of THCV and rimonabant on plasma insulin were not significantly different in wild-type or GPR55 knockout mice at any time point (Figures G, $\mathrm{H}$ and I). ${ }^{*} P<0.05 ; * P<0.01$. 
A

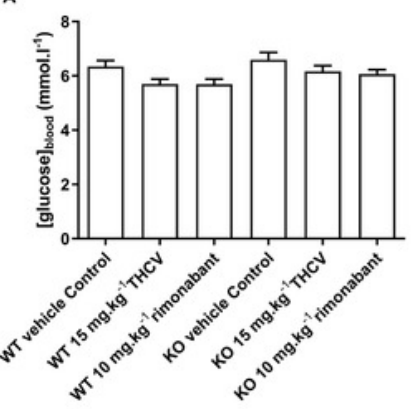

D

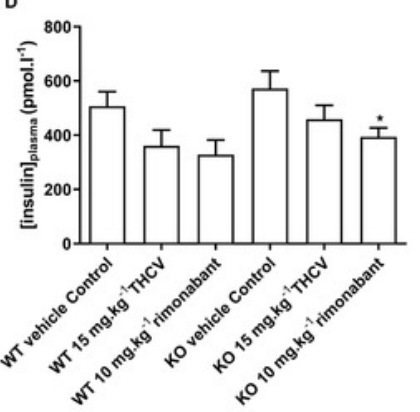

G

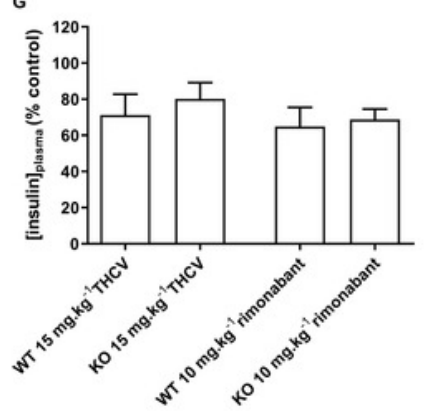

B

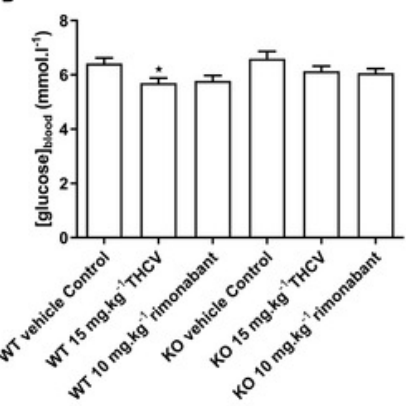

E

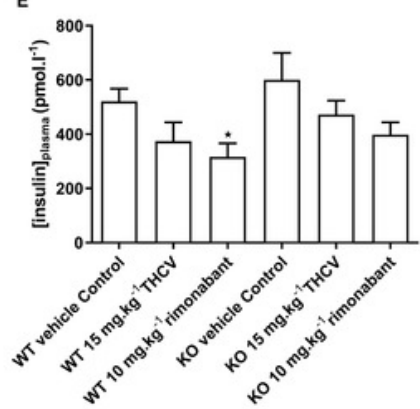

$\mathrm{H}$

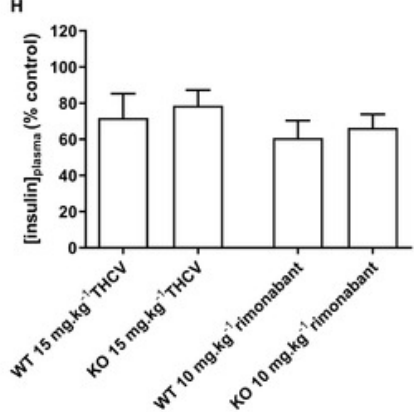

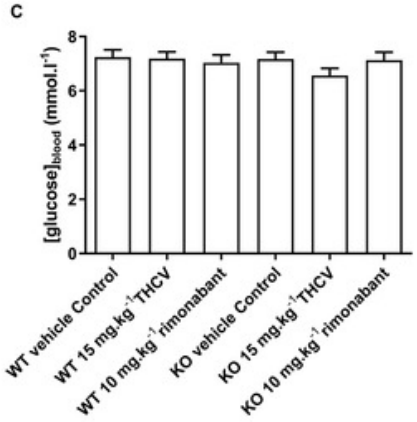
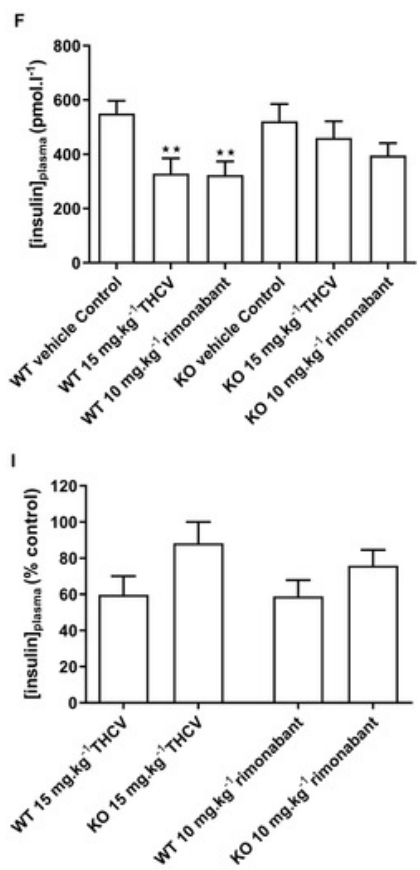